\title{
Horseradish peroxidase-conjugated-nanobody- based blocking ELISA for the rapid and sensitive clinical detection of African swine fever virus antibodies
}

\section{Huijun Zhao}

Henan Agricultural University

Jiahui Ren

Henan Agricultural University

Shuya Wu

Henan Agricultural University

Yongkun Du

Henan Agricultural University

\section{Bo Wan}

Henan Agricultural University

Guoqing Zhuang

Henan Agricultural University

Pengchao Ji

Henan Agricultural University

\section{Yanan Wu}

Henan Agricultural University

Angke Zhang ( $\square$ zhangangke1112@126.com )

Henan Agricultural University https://orcid.org/0000-0002-2696-8007

\section{Gaiping Zhang}

Henan Agricultural University

\section{Methodology}

Keywords: nanobody, blocking enzyme-linked immunosorbent assay, African swine fever virus, serum antibody

Posted Date: August 6th, 2021

DOI: https://doi.org/10.21203/rs.3.rs-730270/v1 
License: (c) (i) This work is licensed under a Creative Commons Attribution 4.0 International License. Read Full License 


\section{Abstract \\ Background}

African swine fever (ASF), which is caused by the ASF virus (ASFV), is a highly contagious hemorrhagic disease that affects pigs and has the potential to cause mortality in almost $100 \%$ of domestic pigs and wild boars. Due to the lack of an effective vaccine, the control of ASF must depend on early, efficient, cost-effective detection and strict control and elimination strategies. Traditional molecular and serological testing methods are generally associated with high testing costs, complex operations and high technical requirements. As a promising alternative diagnostic tool to traditional antibodies, nanobodies $(\mathrm{Nb})$ have the advantages of simpler and faster generation, good stability and solubility, and high affinity and specificity. The application of Nbs in the detection of ASFV antibodies in the serum has not yet been reported, to the best of our knowledge.

\section{Results}

Using a phage display technology, one specific Nb against the ASFV p54 protein that exhibited high specificity and affinity to the protein, $\mathrm{Nb83}$, was successfully screened. Nb83 was labeled with horseradish peroxidase (HRP) to create an Nb83-HRP fusion protein in 293T cells. Following the optimization of the reaction conditions, the Nb83-HRP fusion protein was successfully used to establish a blocking enzyme-linked immunosorbent assay (ELISA) to detect ASFV-specific antibodies in pig serum, for the first time. The cutoff value for the blocking ELISA was $39.16 \%$. A total of 210 serum samples were tested using the developed blocking ELISA and a commercial ELISA kit. The specificity of the blocking ELISA was $100 \%$, and the limit of detection was 1:5,120 in inactivated ASFV antibody-positive reference serum samples, with the coincidence rate between the two methods being $98.57 \%$.

\section{Conclusions}

A specific, sensitive and repeatable blocking ELISA was successfully developed based on the unique $\mathrm{Nb}$ as a probe, providing a promising method for the detection of anti-ASFV antibodies in clinical pig serum.

\section{Introduction}

African swine fever (ASF), which is caused by ASF virus (ASFV), is a highly contagious hemorrhagic viral disease afflicting domestic pigs and wild boars. The infection of ASFV usually results in a mortality rate of $\sim 100 \%$ in pigs, rendering ASF the most significant threat to the global pig industry. In fact, ASF has been classified as a notifiable disease by the World Organization for Animal Health $(\mathrm{OIE})(1,2)$. Since the first reported outbreak in China in August 2018, ASF has been detected in more than eight other countries in Asia and has resulted in the death or culling of $>1,192,000$ pigs, with losses accounting for $>10 \%$ of the total pig population in China, Mongolia and Vietnam $(3,4)$. The most recent outbreak of ASF in China and 
Southeast Asia, along with the infection of wild boar in Belgium, has created a sense of urgency for the development and use of cost-effective approaches that can prevent the entry of ASFV into countries and areas where the virus has not spread.

ASFV is an enveloped, icosahedral virus that contains a double-stranded DNA genome with a length of 170-194 kb (2,5); it is the only member of the Asfarviridae family and Asfivirus genus. Thus far, $>150$ unique proteins have been identified from ASFV-infected pig macrophage tissue culture, of which $\geq 50$ have been found to react with serum from pigs that have recovered from ASF (6). In the acute form of the ASFV infection, particularly in naive populations, death usually occurs prior to the proliferation of antibodies to a detectable level $(7,8)$. However, in enzootic areas affected by ASF, particularly subacute infections, surviving animals may maintain a detectable level of antibodies post-infection and serve as carriers of the virus $(9,10)$. Since there is currently no commercially available vaccine for ASF, the presence of antibodies in the serum is a definitive indicator of infection, and their detection is critical for the control of viruses in infected herds, as well as for surveillance to track the absence of disease.

The effective control of ASF is based on early diagnosis and the enforcement of strict sanitary measures. Molecular diagnostic technologies, including polymerase chain reaction (PCR) or quantitative PCR (qPCR), are very effective in the early diagnosis and prevention of ASF (11-13). However, despite PCR and qPCR being the gold standard for ASFV detection in the laboratory, they require thermal cycling instruments and skilled operators, which is not ideal for resource-limited situations. In addition, other molecular diagnostic methods, including the invader assay (14), loop-mediated isothermal amplification $(15,16)$, recombinase polymerase amplification (17), and methods of detecting ASFV antigens based on the CRISPR system $(18,19)$, have been developed. Although these methods exhibit high sensitivity and specificity, the majority of them are time-consuming, laborious and costly, which are limitations that seriously hinder their clinical application.

Serological diagnostic methods are still the main means for ASF diagnosis and control. At present, the routine, OIE-approved, diagnostic method for ASF is enzyme-linked immunosorbent assay (ELISA) after preliminary screening, followed by western blotting $(20,21)$. The viral antigens in the OIE-approved detection methods are derived from live viruses, a process that requires a level 3 biosafety laboratory $(22,23)$. In addition, numerous ELISA-based serological tests using the structural and highly immunogenic protein $\mathrm{p} 30$, the major capsid protein $\mathrm{p} 72$, and other antigens that can induce higher levels of antibodies can be used for the detection of ASFV antibodies (24-26). In addition, the structural and immunogenic p54 protein is used for serological diagnosis, since anti-p54 antibodies have been shown to appear as early as 8 days after infection and persist for several weeks $(27,28)$. However, limitations in sensitivity, specificity, simplicity and expenditure continue to restrict the use of traditional ELISA for research and clinical purposes.

Monoclonal antibodies (mAbs) comprise the largest and most widely used type of diagnostic antibodies in the serological diagnosis of viral diseases. Nevertheless, their clinical application is hampered by the time-consuming and costly process of antibody manufacturing using eukaryotic systems. A well-known 
reason for this is the fact that the large-scale production of mAbs typically takes $>3-6$ months, making timely production difficult in an epidemic setting, such as that of ASF.

The most promising alternative to mAbs is single-domain antibodies, also known as heavy-chain variable domains $(\mathrm{VHH})$ or nanobodies (Nbs), which are produced in camels. Unlike ordinary IgG antibodies, Nbs have a small molecular weight $(\sim 15 \mathrm{kDa})$ and are highly soluble and stable. They are also readily bioengineered into bi/multivalent forms, have relatively low production costs and can be rapidly and efficiently produced in prokaryotic expression systems (29). Nbs might be better suited to access hidden targets and cryptic sites than normal antibodies (30). In addition, Nbs bind to their targets with high affinity and specificity, due to having an extended antigen-binding region $(31,32)$. Based on their advantages over conventional antibodies, Nbs are promising candidates for various biomedical applications, such as disease diagnosis and treatment (33-36). Furthermore, certain studies have shown that $\mathrm{Nbs}$ are superior to traditional antibodies in the development of new viral antigen or antibody detection methods, such as the $\mathrm{Nb}$-based rapid single-molecule detection of coronavirus disease 2019 and middle east respiratory syndrome antigens (37).

Thus far, to the best of our knowledge, no specific Nbs against ASFV structural or non-structural proteins have been reported. Considering the broad application prospects of Nbs in pathogen detection, a novel $\mathrm{Nb}$ against p54 protein, $\mathrm{Nb83}$, was generated in the present study, through the immunization of a Bactrian camel with recombinant ASFV p54 protein and phage display technology. Nb83 was then conjugated with horseradish peroxidase (HRP) to create the Nb83-HRP recombinant protein, which was further used as a probe to establish the blocking ELISA for the detection of ASFV antibodies in inactivated pig serum samples. The results showed that the established blocking ELISA exhibited high specificity and repeatability. It also exhibited superior sensitivity to that of conventional ELISA methods, thus demonstrating a promising application potential in future clinical pig serum detection.

\section{Materials And Methods}

\section{Expression and purification of recombinant ASFV p54 protein}

To prepare the antigen used for camel immunization, a pET-30 prokaryotic expression system was used to express recombinant ASFV p54 protein. Following the construction of the recombinant plasmid, pET30-p54-His, the plasmids were sequenced, and the correct plasmids were transferred into Transetta (DE3) expression competent cells (TransGen Biotech, Beijing, China). A single clone was selected and treated with $1.0 \mathrm{mM}$ isopropyl $\beta$-D-1-thiogalactopyranoside (IPTG) at $37^{\circ} \mathrm{C}$ for $12 \mathrm{~h}$. Following ultrasonication, the lysates were centrifuged at $12,000 \times \mathrm{g}$ for $30 \mathrm{~min}$ at $4^{\circ} \mathrm{C}$, and precipitates and supernatants were subjected to SDS-PAGE and western blot analysis, respectively.

The ASFV p54 protein was purified using cOmplete His-Tag Purification Resin (Roche, Basel, Switzerland). Before protein purification, the resin was equilibrated with 10 times column volumes of buffer $\mathrm{A}\left(50 \mathrm{mM} \mathrm{NaH}_{2} \mathrm{PO}_{4} \mathrm{pH}=8,300 \mathrm{mM} \mathrm{NaCl}\right)$. Then the contaminated proteins were eluted with buffer 
A containing $20 \mathrm{mM}$ imidazole, and the p54 protein was eluted with buffer A containing $250 \mathrm{mM}$ imidazole. The eluted product was collected and analyzed by SDS-PAGE.

\section{Immunization and construction of the Nb library}

A Bactrian camel was first immunized with a mixture of $5 \mathrm{ml} \mathrm{p} 54$ protein $(5 \mathrm{mg})$ and an equal volume of Freund's complete adjuvant (Sigma-Aldrich, Merck KGaA, St. Louis, MO, USA). For the subsequent immunizations, p54 protein was mixed with an equal volume of Freund's incomplete adjuvant (SigmaAldrich, Merck KGaA, St. Louis, MO, USA); immunizations were performed at 2-week intervals, four times. A week after the forth immunization, $300 \mathrm{ml}$ whole blood was collected, and peripheral blood lymphocytes (PBLs) were separated from $200 \mathrm{ml}$ whole blood using Ficoll-Paque PLUS (Cytiva) with Leucosep $^{\text {TM }}$ tubes (Greiner Bio-One $\mathrm{GmbH}$ ). The remaining $100 \mathrm{ml}$ whole blood was used for serum isolation and immunization titer detection. All camel experiments were performed according to guidelines approved by the Animal Care and Use Committee of Henan Agricultural University (Zhengzhou, China).

For library construction, total RNA from PBLs was extracted using an RNeasy ${ }^{\circledR}$ Plus Mini kit (Qiagen AB). cDNA was reverse transcribed using a SuperScript III First-Strand Synthesis system (Thermo Fisher Scientific, Inc.). An 700-bp target band spanning the $\mathrm{VHH}-\mathrm{CH} 2$ exons was cloned during the first round of PCR. The VHH encoding sequences ( $400 \mathrm{bp}$ ) were amplified using the products from the first PCR as a template and then purified using agarose gel electrophoresis. Following digestion with Pstl and Nott, the target segments were cloned into the phage display vector pCANTAB-5E (Cytiva) and then electrotransformed into freshly prepared $E$. coli TG1 competent cells. The transformation products were cultured in solid 2X YT medium containing $100 \mu \mathrm{g} / \mathrm{ml}$ ampicillin and $2 \%(\mathrm{w} / \mathrm{v})$ glucose overnight at $37^{\circ} \mathrm{C}$. The colonies were scraped from the plates, placed into $3 \mathrm{ml}$ liquid Luria-Bertani (LB) medium (Oxoid) supplemented with $20 \%(\mathrm{v} / \mathrm{v})$ glycerol and stored at $-80^{\circ} \mathrm{C}$. Following a gradient dilution, the capacity of the constructed library was detected by counting the number of colonies.

\section{Library screening using phage display}

The specific Nbs against ASFV p54 protein were screened via three consecutive rounds of biopanning with the 554 protein. Briefly, 1x10 10 TG1 cells (Beyotime Biotech, Shanghai, China) from the library stock were recovered and cultured in 2 X YT medium containing $100 \mu \mathrm{g} / \mathrm{ml}$ ampicillin and $2 \%(\mathrm{w} / \mathrm{v})$ glucose for $2 \mathrm{~h}$ at $37^{\circ} \mathrm{C}$. Then, the TG1 cells were infected with M13K07 Helper Phage (New England Biolabs, Ipswich, MA, USA $)\left(1.8 \times 10^{13} \mathrm{pfu} / \mathrm{ml}\right)$ and incubated at $37^{\circ} \mathrm{C}$ for $1 \mathrm{~h}$ without shaking. Cells were collected using centrifugation at $3,000 \mathrm{xg}$ for $10 \mathrm{~min}$ at room temperature, followed by resuspending into $2 X$ YT medium supplemented with $50 \mu \mathrm{g} / \mathrm{ml}$ kanamycin and $100 \mu \mathrm{g} / \mathrm{ml}$ ampicillin, which were cultured overnight at $37^{\circ} \mathrm{C}$ at $220 \mathrm{rpm}$. The phages in the supernatant were precipitated using PEG $6000 / \mathrm{NaCl}$ for $3 \mathrm{~h}$ on ice, and were then centrifuged at $12,000 \times \mathrm{g}$ for $30 \mathrm{~min}$ at $4^{\circ} \mathrm{C}$ and resuspended in sterile PBS. The phages were quantified using phage titration. For every round of biopanning, $\sim 5 \times 10^{11} \mathrm{pfu} / \mathrm{ml}$ phages were incubated in 96 -well plates (Thermo Fisher Scientific, Inc.) coated with p54 protein $(10 \mu \mathrm{g} / \mathrm{well})$. The enrichment of specific phage particles was monitored using an anti-M13 HRP-conjugated antibody (Sino 
Biological, 1:2000) for ELISA and phage titration, as previously reported (30). After three consecutive rounds of biopanning, the enrichment of specific phage particles was calculated, and 96 individual colonies were randomly selected and treated with $1.0 \mathrm{mM} \mathrm{IPTG}$. The positive clones expressing E-Tag p54-specific Nbs were identified using periplasmic extract ELISA (PE-ELISA) with an anti-E-Tag antibody (GenScript, 1:2000). If the absorbance in the antigen-coated well was $>3$-fold higher than that of the well containing PBS, the colony was regarded as positive. The identified positive clones were then sequenced, and the amino acid sequences of Nbs were analyzed and classified into different groups, based on their sequence diversity in third complementarity-determining (CDR3) regions.

\section{Production of Nb-HRP recombinant protein against the ASFV p54 protein}

HRP-conjugated recombinant $\mathrm{Nb}$ was prepared, according to previous reports with some modifications (38). Specific DNA sequences, including a signal sequence for protein secretion derived from the human Ig kappa chain, which promotes the extracellular secretion of fusion proteins, and a codon-optimized HRP gene sequence, were synthesized and fused with the $\mathrm{Nb}$ gene amplified from the recombinant PCANTAB-5E vector using overlap extension PCR. Following digestion with EcoRI and Nhel, the fusion fragments were inserted into the multiple cloning sites of the pCAGGS-hemagglutinin (HA) eukaryotic expression vector, termed pCAGGS-Nb-HRP in the following experiment. Following sequencing, the recombinant plasmid was transfected into 293T cells using polyetherimide reagents (Polysciences Inc.). At $48 \mathrm{~h}$ following transfection, cells and supernatants containing the Nb-HRP recombinant protein were harvested and analyzed using western blotting or an indirect fluorescence assay (IFA) to determine the $\mathrm{Nb}$-HRP recombinant protein expression. Supernatants were filtered using a $0.22-\mu \mathrm{m}$ filter membrane for further use.

For western blotting, the 293T cells were harvested $60 \mathrm{~h}$ post-transfection for analysis using mouse antiHA mAb (Beyotime Institute of Biotechnology, Shanghai, China; 1:1000) as the primary antibody and HRP-conjugated goat anti-mouse IgG (Jackson ImmunoResearch Laboratories, Inc.; 1:2000) as the secondary antibody. For IFA, at $36 \mathrm{~h}$ post-transfection, the $293 \mathrm{~T}$ cells were fixed with $-20^{\circ} \mathrm{C}$ pre-cooled $70 \%$ alcohol and probed with mouse anti-HA mAb, followed by incubation with Alexa Fluor 594-conjugated goat anti-mouse IgG (H\&L). The cells were then observed under a fluorescence microscope (Leica AF6000; Leica Microsystems GmbH, 200x). For ELISA analysis of the Nb-HRP recombinant protein in the supernatant, 100 and $200 \mu \mathrm{l}$ supernatant with or without plasmid transfection, respectively was directly incubated in 96-well ELISA plates at $4^{\circ} \mathrm{C}$ overnight. Following washing with PBS Tween 20 (PBST) three times, $100 \mu$ l tetramethylbenzidine (TMB) was added to each well and incubated at $37^{\circ} \mathrm{C}$ for $15 \mathrm{~min}$ in the dark. Next, $50 \mu \mathrm{l} /$ well of $3 \mathrm{M} \mathrm{H}_{2} \mathrm{SO}_{4}$ was added to stop the reaction, and the absorbance of the plate was measured at OD450 nm using a spectrophotometer (PerkinElmer, Inc.).

\section{Specificity analysis of Nb-HRP recombinant protein against p54 protein}

For specificity analysis, 96-well plates were coated with ASFV p54 protein, porcine reproductive and respiratory syndrome virus (PRRSV) N protein, PEDV N protein and ASFV p30 protein at a density of 200 
ng/well at $4^{\circ} \mathrm{C}$ overnight. Following blocking with $2.5 \%$ dried milk at $37^{\circ} \mathrm{C}$ for $1 \mathrm{~h}$, supernatants collected from pCAGGS-Nb-HRP-transfected 293T cells were added $\left(100 \mu \mathrm{l} /\right.$ well) and incubated at $37^{\circ} \mathrm{C}$ for $1 \mathrm{~h}$, followed by washing with PBST three times. A total of $100 \mu \mathrm{l} /$ well TMB was added and incubated at $37^{\circ} \mathrm{C}$ for $15 \mathrm{~min}$ in the dark. Finally, $50 \mu \mathrm{l} /$ well $3 \mathrm{M} \mathrm{H}_{2} \mathrm{SO}_{4}$ was added to stop the reaction and absorbance was measured at $450 \mathrm{~nm}$ (PerkinElmer, Inc.).

\section{Analysis of the affinity of Nb-HRP recombinant protein based on the OD450 value}

The kinetic characteristics of $\mathrm{Nb}-\mathrm{HRP}$ in cell culture supernatants bound to recombinant p54 protein were determined using indirect ELISA. Briefly, 96-well plates coated with the purified recombinant p54 protein (200 ng/well) were incubated at $4^{\circ} \mathrm{C}$ overnight. The plates were washed with PBST three times and incubated with serial dilutions of Nb-HRP supernatants $(1: 5,1: 10,1: 20,1: 40,1: 80$ and 1:160) for $1 \mathrm{~h}$ at $37^{\circ} \mathrm{C}$. After washing three times with PBST, $100 \mu \mathrm{l} /$ well TMB was added, followed by incubation at $37^{\circ} \mathrm{C}$ for $15 \mathrm{~min}$ in the dark. The reaction was stopped by the addition of $50 \mu \mathrm{l} /$ well of $3 \mathrm{M} \mathrm{H}_{2} \mathrm{SO}_{4}$ and absorbance was measured at OD450 nm. The affinity of specific Nb-HRP was analyzed based on the OD450 value.

\section{Development of the blocking ELISA using Nb-HRP recombinant protein as a probe}

Based on the specific Nb-HRP recombinant protein, a blocking ELISA was established for the detection of ASFV p54 antibodies in the serum. To optimize the detection effect, the optimal concentration of p54 protein and dilution ratio of supernatant $\mathrm{Nb}$-HRP were first determined using direct ELISA via the checkerboard method. A serial dilution of p54 protein (10, 20, 40, 80, 160, 320 and $640 \mathrm{ng} / \mathrm{well})$ and supernatant Nb-HRP (supernatant stock, 1:20, 1:50, 1:100, 1:200, 1:400 and 1:800) were performed simultaneously. The combination at an OD450 of 1.0 was determined to be the optimal antigen coating amount and Nb-HRP dilution ratio.

Next, the optimal dilution ratio of the serum to be tested was determined. According to the determined optimal working concentration of p54 protein and Nb-HRP, three separated inactivated ASFV antibodypositive (No. 1-3) and three negative serum (No. 4-6) samples were selected and diluted at 1:5, 1:10, 1:20, $1: 40,1: 80,1: 160$ and $1: 320$ for blocking ELISA detection. They were then added to the wells at $37^{\circ} \mathrm{C}$ for different durations $(15,30,45,60,90$ and $120 \mathrm{~min})$. Then, the plate was washed three times with PBST, and $\mathrm{Nb}$-HRP was added to the wells and incubated for different durations (30, 45, 60, 90 and $120 \mathrm{~min}$ ). Following another three times washing with PBST, $100 \mu$ freshly prepared TMB solution was added to the plate, which was incubated at $37^{\circ} \mathrm{C}$ for 5,10 or $15 \mathrm{~min}$. The reaction was stopped by the addition of $50 \mu \mathrm{l}$ $3 \mathrm{M} \mathrm{H}_{2} \mathrm{SO}_{4}$, and the absorbance was measured at OD450 nm using a microplate reader. If the percentage inhibition $(\mathrm{PI})=100 \times$ [negative serum OD450 value - (test serum OD450 value / negative reference serum OD450 value)] was the highest and the absorbance of the negative serum was the closest to 1.0 , the experimental conditions were considered optimal.

\section{Establishment of blocking ELISA}


Based on the optimized reaction conditions, a blocking ELISA was developed as follows: 96-well plates were coated with the optimal concentration of purified p54 protein overnight at $4^{\circ} \mathrm{C}$. After discarding the coating buffer and washing three times with PBST (300 $\mu \mathrm{l} /$ well), the plates were blocked with $2.5 \%$ dried milk $\left(200 \mu \mathrm{l} /\right.$ well) for $1 \mathrm{~h}$ at $37^{\circ} \mathrm{C}$. Following washing three times with PBST (300 $\mu \mathrm{l} /$ well), serum samples to be tested were added to the wells at the optimal dilution ratio $(100 \mu \mathrm{l} /$ well $)$ and incubated at $37^{\circ} \mathrm{C}$ for the optimal duration. The plates were washed three times with PBST and Nb-HRP recombinant protein at the optimal dilution was added to the plates and incubated at $37^{\circ} \mathrm{C}$ for the optimal duration. Following washing three times with PBST, $100 \mu \mathrm{l} /$ well fresh TMB was added to the well plate and incubated at $37^{\circ} \mathrm{C}$ for the optimal duration. Next, $50 \mu \mathrm{l} /$ well $3 \mathrm{M} \mathrm{H}_{2} \mathrm{SO}_{4}$ was added to each well to stop the reaction, and the absorbance value was detected at OD450 nm. The blocking rate was calculated according to the serum OD450 value. The serum PI was then calculated using the aforementioned equation.

\section{Determination of the cutoff value of blocking ELISA}

A total of 152 serum samples confirmed as standard ASFV-negative using both RT-PCR and a commercial ELISA kit (Beijing Jinnuobaitai Biotechnology, Beijing, China) were used to determine the cutoff values for a positive and negative result for the blocking ELISA. The established blocking ELISA method was used to detect ASFV antibody-negative serum, in which the dilution of Nb-HRP and serum was determined. The serum blocking rate was then calculated. According to the statistical method, the test result was analyzed using the following formula: Negative-positive critical value $=+3 S D$, where is the average value of the blocking rate of negative serum and SD is the SD of the blocking rate of negative serum. Serum samples with PI values greater than or equal to the negative-positive critical value were considered ASFV antibody-positive. Serum samples with PI values less than the negativepositive critical value were considered ASFV-antibody negative.

\section{Specificity, sensitivity and repeatability of blocking ELISA}

To determine the specificity of the blocking ELISA, PRRSV, pseudorabies virus (PRV), PEDV, porcine transmissible gastroenteritis virus (TGEV), porcine parvovirus (PPV), classical swine fever virus (CSFV) and inactivated ASFV antibody-positive pig serum samples, were confirmed using RT-PCR, a commercial ELISA kit and the developed blocking ELISA. Next, 96-well plates were coated with the optimal ASFV p54 protein concentration at $4^{\circ} \mathrm{C}$ overnight, and the blocking ELISA was conducted as described previously.

To test the sensitivity of the blocking ELISA, three serum samples confirmed as ASFV antibody-positive using RT-PCR and the commercial ELISA kit were serially diluted $(1: 5,1: 10,1: 20,1: 40,1: 80,1: 160,1: 320$, $1: 640,1: 1,280,1: 2,560,1: 5,120,1: 10,240$ and $1: 20,480$ ) and tested using blocking ELISA to determine the lowest limit detection.

The established blocking ELISA method was used to perform a repeatability test six times on the same test plate and different test plates from those used for the three inactivated ASFV antibody-negative serum samples and three inactivated ASFV antibody-positive serum samples. For the intra-assay repeatability test, the swine serum samples were detected using a blocking ELISA. The same batch of p54 
protein-coated ELISA plates was tested three times in triplicate wells for each sample, and the OD450 value was detected. For the inter-assay repeatability test, different batches of plates were tested separately three times in triplicate wells for each sample, the OD450 value was detected and the PI value was calculated.

\section{Detection of field serum samples}

A total of 210 clinical porcine field serum samples collected from three farms in the Henan and Hebei provinces between 2019 and 2020 were tested using the developed blocking ELISA and commercial ELISA kit, as previously described and following the manufacturer's instructions, respectively. The coincidence rates between the developed blocking ELISA and the commercial ELISA kit (Beijing Jinnuobaitai Biotechnology) were calculated using Microsoft Excel's Correl function (Microsoft Corporation).

\section{Statistical analysis}

Statistical analysis was performed using GraphPad Prism version 6.0 software (GraphPad Software, Inc.). Data are expressed as the mean \pm SD. Kappa values were calculated to estimate the coincidence between the developed blocking ELISA and the commercial ELISA kit using SPSS software version 20 (IBM Corp.; http://www.spss.com.cn).

\section{Results}

\section{Expression and purification of recombinant ASFV p54 protein}

ASFV p54 protein was expressed and purified as described in the 'Materials and methods' section. The purified p54 protein was analyzed using SDS-PAGE and western blotting. SDS-PAGE results showed that the p54 protein was successfully expressed, and was mostly distributed in the supernatant, with only a small amount distributed in the precipitates (Fig. 2A). Following purification using the cOmplete His-Tag Purification Resin, most proteins that were related to E.coli proteins were removed, resulting in the high purity of the p54 protein (Fig. 2A). In addition, western blotting results showed that p54 was able to react with the inactivated ASFV antibody-positive pig serum (Fig. 2B). Finally, after buffer exchange to PBS, about $50 \mathrm{mg}$ of purified p54 protein was obtained. The p54 protein was aliquoted and stored at $-80^{\circ} \mathrm{C}$ for further use.

\section{Construction and verification of phage display VHH library}

The purified p54 protein was used to immunize a four years old male bactrian camel. A total of four immunizations were conducted, and dose was $5.0 \mathrm{mg}$ for each immunization (Fig. 1). One week after the last immunization, polyclonal antiserum was extracted and the titer was evaluated by indirect ELISA. ELISA results showed that the titer of the antiserum was 1:256000, indicating that the immunization was successful (Fig. 3A). Then the whole blood was collected and PBLs was separated, total RNA was 
extracted and transcripted into CDNA, which was used as the template of PCR. After one round of PCR, about 700 bp of target band was obtained (Fig. 3B). Then the target band was harvested for the second round of PCR. As showed in Fig. 3C, about 400 bp of VHH target band was amplified.

\section{Biopanning and specific $\mathrm{Nb}$ screening}

To screen specific Nbs against ASFV p54 protein from the phage display VHH library, three consecutive rounds of biopanning were conducted using phage ELISA coated with p54 protein as the antigen. Following three rounds of biopanning, phage particles carrying the specific VHH genes were found to be markedly enriched (Table 1). Next, to obtain soluble Nbs with high specificity and affinity, 96 individual colonies were selected from the culture plate used in the third round of biopanning and treated with IPTG (Fig. 3D and E). The periplasmic extracts from the 96 clones were subjected to indirect PE-ELISA to identify whether they could bind to the p54 protein. The results showed that, among the 96 clones, 93 could specifically react with p54 protein compared with the negative control (Fig. 4A). These specific clones were sequenced for $\mathrm{VHH}$ genes, and sequence analysis results indicated that a total of 5 specific $\mathrm{Nbs}(\mathrm{Nb} 2, \mathrm{Nb83}, \mathrm{Nb86}, \mathrm{Nb} 89$ and $\mathrm{Nb96}$ ) were screened and identified based on the CDR3 region of $\mathrm{VHH}$ genes (Fig. 4B). Amino acid sequence analysis revealed that conserved residues at the 37, 44, 45 and 47 positions (located on the VH-VL interface region of $\mathrm{VHs}$ ) from the five Nbs were identified to be hydrophilic amino acids (Fig. 4B). To further confirm which $\mathrm{Nb}$ had the best reaction activity and specificity, whether the five Nbs reacted with PRRSV N, PEDV N and ASFV p30 proteins was determined firstly using indirect ELISA. The results showed that none of the five Nbs reacted with these unrelated proteins. Nevertheless, when the indirect ELISA was performed using p54 protein, Nb83 exhibited the highest reactivity with p54 protein (Fig. 4C). The affinity of these Nbs to p54 protein was further investigated through the serial dilution of supernatants containing them. As shown in Fig. 4D, $\mathrm{Nb83}$ exhibited the highest affinity. Based on the specificity and affinity identification results, Nb83 was selected for the development of the blocking ELISA.

\section{Generation of HRP-conjugated recombinant Nb83 in HEK-293T cells}

The Nb83 gene was amplified from the pCANTAB-5E vector and fused with the HRP gene, and then cloned into the PCAGGS-HA vector to construct the PCAGGS-Nb83-HRP recombinant plasmid (Fig. 5A-C). The correct sequenced plasmids were transfected into $293 \mathrm{~T}$ cells. At $60 \mathrm{~h}$ post-transfection, cells and supernatants were harvested for western blotting and direct ELISA analysis of Nb83-HRP fusion protein expression. As shown in Fig. 6A, western blotting results showed that Nb83-HRP fusion protein was expressed in the pCAGGS-Nb83-HRP-transfected 293T cells. IFA yielded similar results (Fig. 6B). Direct ELISA analysis of cell culture supernatants revealed that Nb83-HRP fusion protein was secreted into cell culture supernatants, and Nb83-HRP fusion protein could specifically react with p54 protein, but not with other unrelated proteins (Fig. 6C). In addition, direct ELISA analysis of the Nb83-HRP fusion protein affinity suggested that the Nb83-HRP fusion protein had a high binding affinity for the p54 protein (Fig. $6 \mathrm{D})$.

\section{Development of blocking ELISA using the Nb83-HRP as a probe}

Page $11 / 31$ 
Based on the optimized reaction conditions (Fig. 7), the blocking ELISA procedure was performed as follows: 96 -well plates were coated with $320 \mathrm{ng} /$ well purified p54 protein overnight at $4^{\circ} \mathrm{C}$. Following washing three times with PBST, the plates were blocked with $200 \mu \mathrm{l} /$ well of $2.5 \%$ dried milk for $1 \mathrm{~h}$ at $37^{\circ} \mathrm{C}$, followed by further washing three times with PBST. Serum samples to be tested were added to the wells at a dilution of $1: 5,100 \mu \mathrm{l} /$ well and incubated at $37^{\circ} \mathrm{C}$ for $2 \mathrm{~h}$. The plates were washed three times with PBST, and then $100 \mu \mathrm{l} /$ well Nb83-HRP supernatant was added and incubated at $37^{\circ} \mathrm{C}$ for $30 \mathrm{~min}$. Following washing three times with PBST, $100 \mu \mathrm{l} /$ well fresh TMB was added and incubated at $37^{\circ} \mathrm{C}$ for 5 min. Finally, $50 \mu \mathrm{l} /$ well $3 \mathrm{M} \mathrm{H}_{2} \mathrm{SO}_{4}$ was added to each well to stop the reaction, and the absorbance value was detected at OD450 nm (Fig. 1B).

\section{Determination of cutoff value for blocking ELISA}

To determine the cutoff value of the blocking ELISA, 152 standard ASFV antibody-negative serum samples were detected using a blocking ELISA. The results showed that the average PI ( ) of the negative serum samples was $-1.66 \%$, and the SD was $13.61 \%$. Thus, the cutoff value for blocking ELISA was $39.16 \%$. The sample was regarded as ASFV antibody-positive at a PI $\geq 39.16 \%$ and ASFV antibodynegative at a $\mathrm{PI}<25.56 \%$. A blocking rate of $>25.56 \%$ and $<39.16 \%$ indicated that the sample was suspicious and required re-examination.

\section{Specificity, sensitivity and repeatability of blocking ELISA}

Blocking ELISA was used to detect PRRSV, PRV, PEDV, TGEV, PPV and CSFV antibody-positive serum to determine its specificity. A commercial ELISA kit was used to determine the number of PRRSV, PRV, PEDV, TGEV, PPV, CSFV antibody-positive serum samples in the inactivated 210 samples. The ELISA results yielded 187 PRRSV antibody-positive (serum samples following vaccine immunization), five PRV antibody-positive, four PEDV antibody-positive, five TGEV antibody-positive, six PPV antibody-positive and three CSFV antibody-positive samples. The OD450 value of the positive serum samples was detected using the developed blocking ELISA, and the mean value was calculated. The PI of each serum was also calculated. The results suggested that no serum, except the inactivated ASFV antibody-positive serum, exhibited a blocking effect ( $\mathrm{PI}<25.56 \%$; Fig. 8), suggesting that the blocking ELISA was specific to antiserum against ASFV.

The sensitivity of blocking ELISA was evaluated through the detection of three inactivated ASFV antibody-positive serum samples with different dilution gradients. The results showed that the lowest limit of detection of blocking ELISA reached 1:5,120 (Fig. 9), suggesting that the blocking ELISA could be used for the detection of ASFV-positive serum at a maximum dilution of 1:5,120, which suggested that it displayed good sensitivity.

To further determine the repeatability of the blocking ELISA, the intra-assay variability of the PI was calculated by testing three inactivated ASFV antibody-positive and three ASFV antibody-negative serum samples; the test was repeated three times. The results showed that the intra-assay coefficient of variation (CV) of the PI was $-11.21-7.55 \%$, with a median value of $3.10 \%$. To determine the inter-assay 
variability, the six samples were tested in three different plates at different time points, and the inter-assay CV of the PI was $-18.60-3.52 \%$, with a median value of $2.41 \%$ (Fig. 10A and B). These data suggested that blocking ELISA displayed good repeatability.

\section{Detection of clinical serum samples}

To confirm whether the blocking ELISA could be used for clinical serum detection, a total of $210 \mathrm{pig}$ serum samples from pig farms in the Henan and Hebei provinces were inactivated and tested using the developed blocking ELISA (Table 2). The results were compared with those of the commercial ELISA kit. The results revealed 17 ASFV antibody-positive and 193 ASFV antibody-negative serum samples, while the commercial ELISA kit revealed 14 positive and 196 negative serum samples (Table 2). When comparing the blocking ELISA with the commercial ELISA kit, the former was found to have a positive coincidence rate of $[14 /(14+0)]=100 \%$ and a negative coincidence rate of $[193 /(3+193)]=98.47 \%$. The sensitivity coincidence rate was $[14 /(14+0)]=100 \%$ and the specificity coincidence rate was $[193 /(3+193)]=98.47 \%$. Therefore, the overall coincidence rate was $[(14+193) /(14+3+0+193)]=98.57 \%$, which was quite consistent with the commercial kit. Furthermore, Kappa index values revealed a high degree of coincidence between the blocking ELISA and the commercial ELISA kit (kappa value=0.8962), with the results of the developed blocking ELISA being highly similar to those of the commercial kit; however, the blocking ELISA exhibited a higher sensitivity. When the three negative samples from the commercial ELISA kit were subjected to western blotting, all three were found to be positive, since the p54 band was clearly detected in the three samples. Similar results were obtained when using inactivated standard ASFV antibody-positive serum as a positive control (Fig. 11).

\section{Discussion}

ASF is a serious threat to the pig farming industry worldwide, including in China (3). Considering that ASF spreads to surrounding areas, continuous improvements in ASF diagnosis and surveillance are critical for disease containment. Pigs that survive natural infection develop antibodies against ASFV 7-10 days after infection, which are detectable for a long period of time (1). Therefore, despite the critical role of ASFV surveillance, a simpler, more cost-effective approach must be developed based on efficient, low-cost and accurate diagnostic testing. Prior to the development of effective vaccines and treatments against ASF, molecular diagnostic methods and serological detection techniques were considered to be the main means of identifying infected animals and eradicating the potential risk of ASFV infection. The ASFV antibody detection methods recommended by the OIE mainly include ELISA, western blotting and IFA (39). Among them, ELISA is simple, low-cost and more suitable for large-scale field epidemiological investigations $(23,39)$. Polyclonal antibodies or mAbs are commonly used in traditional ELISA, but the quality can be inconsistent among the different batches of polyclonal antibodies, and the industrialized large-scale production process of mAbs is complicated and costly (40). By contrast, Nbs, the variable domains of heavy chain-only antibodies that were first discovered in camelids and sharks (41), can be easily produced in prokaryotic and eukaryotic expression systems, including the low-cost and rapid 293T expression system described herein. In the present study, a novel blocking ELISA was developed to detect 
anti-ASFV antibodies on the basis of HRP-conjugated-Nb. $\mathrm{Nb}$, as a probe, exhibited the same specificity as that of the mAb that acted as the specific probe in the commercial ELISA kit, as well as higher sensitivity and simpler operation. However, of the five $\mathrm{Nbs}$, only $\mathrm{Nb83}$ exhibited high affinity and specificity to the p54 protein, with low affinity and specificity observed in the other four Nbs (Fig. $6 \mathrm{C}$ and D). In addition, the blocking ELISA revealed that $\mathrm{Nb83}$, but not the other four $\mathrm{Nbs}$, had a significant blocking effect. We hypothesized that Nb83 may recognize the same epitope(s) on the p54 protein with p54 antibody in ASFV antibody-positive serum, and the other four Nbs may recognize different epitopes from those of $\mathrm{Nb83}$, or no epitopes at all.

The ASFV proteins commonly used for antigen detection are p10, p30, p32, p54, p72 and p73 (42-44). ASFV p54 protein is a type of structural protein that appears in the early stage of viral replication, plays an important role in maintaining the stability of the virus and can induce cell apoptosis (45). The p54 protein is present throughout the life cycle of the virus and is often used as a tracer protein to study the replication, assembly and invasion of ASF viruses (46). In addition, the dynamic protein-binding domain of ASFV p54 protein is the main neutralization site of serum antibodies (44). Following the comparison of the amino acid sequences of p54 protein with those of other viral proteins, no similar sequences were identified, which suggested that p54 protein is unique to ASFV and is an ideal antigen for the development of diagnostic reagents for ASF and the establishment of specific detection methods. However, it is worth noting that the p54 epitope peptide sequence possesses a high degree of variation among the different ASFV genotypes (47), suggesting that the Nb-based blocking ELISA developed herein using p54 as an antigen may not be suitable for serological detection in pigs infected with other ASFV strains. In the present study, a p54-specific Nb could recognize the p54 protein successfully, but the precise recognition site and whether this site is conserved between different ASFV strains remain unclear. Our future studies will focus on analyzing the p54 epitope map in detail to clarify the molecular mechanism of the recognition of $\mathrm{p} 54$ by $\mathrm{Nb}$ and optimizing the blocking ELISA so that it can be used for the serological detection of different ASFV strains. In addition to p54, there are several ELISA-based serological tests incorporating p72 and p30 antigens, which are the basis for existing commercial assays $(48,49)$. A p54 ELISA-based serological test showed $98 \%$ sensitivity and $97 \%$ specificity compared with the OIE-approved ELISA (50), indicating that p54, p30 and p72 comprise an ideal set of antigen targets for the detection of ASFV antibodies. However, the present study used p54 as the antigen, instead of $p 30$ or p72. Whether p30 or p72 are more specific and can overcome the strong variability between $p 54$ strains in establishing an $\mathrm{Nb}$ blocking ELISA using p30 or p72 as the targets remains unclear and requires further study.

The clinical symptoms and pathological changes of ASF are closely associated with PRRSV, CSFV and other swine diseases. These similarities increase the difficulty of the clinical diagnosis of ASF (51). The blocking ELISA developed herein exhibited excellent specificity and no cross-reactivity with PRRSV-, PRV-, PEDV-, TGEV-, PPV- and CSFV-positive serum (Fig. 8). The newly developed blocking ELISA was also evaluated in terms of its sensitivity, which was proven to be excellent. An intra- and inter-assay comparison also revealed good repeatability. Compared with the commercial ELISA kit, the developed 
blocking ELISA exhibited higher sensitivity, lower production costs, and less preparation time for antibody production.

\section{Conclusions}

In the present study, a novel, rapid, specific and low-cost blocking ELISA was developed based on an HRPconjugated $\mathrm{Nb}$, which can be used to assess clinical serum samples. To the best of our knowledge, this was the first report of an Nb against ASFV and its practical application; therefore, a blocking ELISA may represent a promising diagnostic method for the detection of ASFV antiserum in pig farms.

\section{Declarations}

\section{Acknowledgements}

Not applicable.

\section{Author contributions}

A.Z. and G.Z. conceived and designed the experiments. H.Z. and S.W. performed most of the experiments and data analyses. Y.D., B.W. and G.Z. contributed to data analysis. P.J. and Y.W. provided technical support for experiment implementation.

\section{Funding}

This study was supported by National Natural Science Foundation of China (31941001), Key R\&D and Promotion Projects in Henan Province (202102110099).

\section{Availability of data and materials}

All data generated or analyzed during this study are included in the article.

\section{Consent for publication}

Not applicable.

\section{Competing interests}

The authors declare that they have no competing interests.

\section{References}

1. Sanchez-Vizcaino JM, Mur L, Martinez-Lopez B. African swine fever: an epidemiological update. Transbound Emerg Dis. 2012;59(Suppl 1):27-35. 
2. Dixon LK, Chapman DA, Netherton CL, Upton C. African swine fever virus replication and genomics. Virus Res. 2013;173:3-14.

3. Zhou X, Li N, Luo Y, Liu Y, Miao F, Chen T, Zhang S, Cao P, Li X, Tian K, Qiu HJ, Hu R. Emergence of African Swine Fever in China, 2018. Transbound Emerg Dis. 2018;65:1482-4.

4. Lu G, Pan J, Zhang G. African swine fever virus in Asia: Its rapid spread and potential threat to unaffected countries. J Infect. 2020;80:350-71.

5. Alonso C, Borca M, Dixon L, Revilla Y, Rodriguez F, Escribano JM. Ictv Report C. ICTV Virus Taxonomy Profile: Asfarviridae. J Gen Virol. 2018;99:613-4.

6. Dixon LK, Abrams CC, Bowick G, Goatley LC, Kay-Jackson PC, Chapman D, Liverani E, Nix R, Silk R, Zhang F. African swine fever virus proteins involved in evading host defence systems. Vet Immunol Immunopathol. 2004;100:117-34.

7. Blome S, Gabriel C, Beer M. Pathogenesis of African swine fever in domestic pigs and European wild boar. Virus Research. 2013;173:122-30.

8. Mur L, Igolkin A, Varentsova A, Pershin A, Remyga S, Shevchenko I, Zhukov I, Sanchez-Vizcaino JM. Detection of African Swine Fever Antibodies in Experimental and Field Samples from the Russian Federation: Implications for Control. Transboundary Emerging Diseases. 2016;63:E436-40.

9. Penrith ML, Vosloo W. Review of African swine fever: transmission, spread and control. J S Afr Vet Assoc. 2009;80:58-62.

10. de Carvalho Ferreira HC, Backer JA, Weesendorp E, Klinkenberg D, Stegeman JA, Loeffen WL. Transmission rate of African swine fever virus under experimental conditions. Vet Microbiol. 2013;165:296-304.

11. Aguero M, Fernandez J, Romero L, Mascaraque CS, Arias M, Sanchez-Vizcaino JM. Highly sensitive PCR assay for routine diagnosis of African swine fever virus in clinical samples. Journal of Clinical Microbiology. 2003;41:4431-4.

12. Basto AP, Portugal RS, Nix RJ, Cartaxeiro C, Boinas F, Dixon LK, Leitao A, Martins C. Development of a nested PCR and its internal control for the detection of African swine fever virus (ASFV) in Ornithodoros erraticus. Archives of Virology. 2006;151:819-26.

13. Wang AP, Jia R, Liu YC, Zhou JM, Qi YM, Chen YM, Liu DM, Zhao JG, Shi HN, Zhang J, Zhang GP. Development of a novel quantitative real-time PCR assay with lyophilized powder reagent to detect African swine fever virus in blood samples of domestic pigs in China. Transboundary Emerging Diseases. 2020;67:284-97.

14. Hjertner B, Meehan B, McKillen J, McNeilly F, Belak S. Adaptation of an Invader((R)) assay for the detection of African swine fever virus DNA. Journal of Virological Methods. 2005;124:1-10.

15. James HE, Ebert K, McGonigle R, Reid SM, Boonham N, Tomlinson JA, Hutchings GH, Denyer M, Oura CAL, Dukes JP, King DP. Detection of African swine fever virus by loop-mediated isothermal amplification. Journal of Virological Methods. 2010;164:68-74.

16. Wang DG, Yu JH, Wang YZ, Zhang M, Li P, Liu M, Liu YH. Development of a real-time loop-mediated isothermal amplification (LAMP) assay and visual LAMP assay for detection of African swine fever 
virus (ASFV). Journal of Virological Methods. 2020;276.

17. Wang J, Wang J, Geng Y, Yuan W. A recombinase polymerase amplification-based assay for rapid detection of African swine fever virus. Can J Vet Res. 2017;81:308-12.

18. Wang XY, He S, Zhao N, Liu XH, Cao YC, Zhang GH, Wang G, Guo CH. Development and clinical application of a novel CRISPR-Cas12a based assay for the detection of African swine fever virus. Bmc Microbiology. 2020;20.

19. Tao DG, Liu JJ, Nie XW, Xu BR, Tran-Thi TN, Niu LL, Liu XD, Ruan JX, Lan XC, Peng GQ, Sun LM, Ma YL, Li XY, Li CC, Zhao SH, Xie SS. Application of CRISPR-Cas12a Enhanced Fluorescence Assay Coupled with Nucleic Acid Amplification for the Sensitive Detection of African Swine Fever Virus. Acs Synthetic Biology. 2020;9:2339-50.

20. Pastor MJ, Laviada MD, Sanchez-Vizcaino JM, Escribano JM. Detection of African swine fever virus antibodies by immunoblotting assay. Can J Vet Res. 1989;53:105-7.

21. Pastor MJ, Arias M, Escribano JM. Comparison of two antigens for use in an enzyme-linked immunosorbent assay to detect African swine fever antibody. Am J Vet Res. 1990;51:1540-3.

22. Arabyan E, Kotsynyan A, Hakobyan A, Zakaryan H. Antiviral agents against African swine fever virus. Virus Res. 2019;270:197669.

23. Gallardo C, Nieto R, Soler A, Pelayo V, Fernandez-Pinero J, Markowska-Daniel I, Pridotkas G, Nurmoja I, Granta R, Simon A, Perez C, Martin E, Fernandez-Pacheco P, Arias M. Assessment of African Swine Fever Diagnostic Techniques as a Response to the Epidemic Outbreaks in Eastern European Union Countries: How To Improve Surveillance and Control Programs. J Clin Microbiol. 2015;53:2555-65.

24. Gallardo C, Reis AL, Kalema-Zikusoka G, Malta J, Soler A, Blanco E, Parkhouse RM, Leitao A. Recombinant antigen targets for serodiagnosis of African swine fever. Clin Vaccine Immunol. 2009;16:1012-20.

25. Perez-Filgueira DA, Gonzalez-Camacho F, Gallardo C, Resino-Talavan P, Blanco E, Gomez-Casado E, Alonso $\mathrm{C}$, Escribano JM. Optimization and validation of recombinant serological tests for African swine fever diagnosis based on detection of the p30 protein produced in Trichoplusia ni larvae. Journal of Clinical Microbiology. 2006;44:3114-21.

26. Cubillos C, Gomez-Sebastian S, Moreno N, Nunez MC, Mulumba-Mfumu LK, Quembo CJ, Heath L, Etter EMC, Jori F, Escribano JM, Blanco E. African swine fever virus serodiagnosis: A general review with a focus on the analyses of African serum samples. Virus Research. 2013;173:159-67.

27. Alcaraz C, Rodriguez F, Oviedo JM, Eiras A, De Diego M, Alonso C, Escribano JM. Highly specific confirmatory western blot test for African swine fever virus antibody detection using the recombinant virus protein p54. J Virol Methods. 1995;52:111-9.

28. Perez-Filgueira DM, Gonzalez-Camacho F, Gallardo C, Resino-Talavan P, Blanco E, Gomez-Casado E, Alonso C, Escribano JM. Optimization and validation of recombinant serological tests for African Swine Fever diagnosis based on detection of the p30 protein produced in Trichoplusia ni larvae. J Clin Microbiol. 2006;44:3114-21. 
29. Vincke C, Gutierrez C, Wernery U, Devoogdt N, Hassanzadeh-Ghassabeh G, Muyldermans S. Generation of single domain antibody fragments derived from camelids and generation of manifold constructs. Methods Mol Biol. 2012;907:145-76.

30. Zhu M, Gong X, Hu YH, Ou WJ, Wan YK. Streptavidin-biotin-based directional double Nanobody sandwich ELISA for clinical rapid and sensitive detection of influenza H5N1. Journal of Translational Medicine. 2014;12.

31. Muyldermans S. Nanobodies: natural single-domain antibodies. Annu Rev Biochem. 2013;82:77597.

32. Steeland S, Vandenbroucke RE, Libert C. Nanobodies as therapeutics: big opportunities for small antibodies. Drug Discovery Today. 2016;21:1076-113.

33. Salvador JP, Vilaplana L, Marco MP. Nanobody: outstanding features for diagnostic and therapeutic applications. Anal Bioanal Chem. 2019;411:1703-13.

34. Xiang YF, Nambulli S, Xiao ZY, Liu H, Sang Z, Duprex WP, Schneidman-Duhovny D, Zhang C, Shi Y. Versatile and multivalent nanobodies efficiently neutralize SARS-CoV-2. Science. 2020;370.

35. Wu Y, Li C, Xia S, Tian X, Kong Y, Wang Z, Gu C, Zhang R, Tu C, Xie Y, Yang Z, Lu L, Jiang S, Ying T. Identification of Human Single-Domain Antibodies against SARS-CoV-2. Cell Host Microbe. 2020;27:891-8. e895.

36. Zhao G, He L, Sun S, Qiu H, Tai W, Chen J, Li J, Chen Y, Guo Y, Wang Y, Shang J, Ji K, Fan R, Du E, Jiang S, Li F, Du L, Zhou Y. A Novel Nanobody Targeting Middle East Respiratory Syndrome Coronavirus (MERS-CoV) Receptor-Binding Domain Has Potent Cross-Neutralizing Activity and Protective Efficacy against MERS-CoV. J Virol. 2018;92.

37. Guo K, Wustoni S, Koklu A, Diaz-Galicia E, Moser M, Hama A, Alqahtani AA, Ahmad AN, Alhamlan FS, Shuaib M, Pain A, McCulloch I, Arold ST, Grunberg R, Inal S. Rapid single-molecule detection of COVID-19 and MERS antigens via nanobody-functionalized organic electrochemical transistors. Nat Biomed Eng. 2021.

38. Yamagata M, Sanes JR. Reporter-nanobody fusions (RANbodies) as versatile, small, sensitive immunohistochemical reagents. Proceedings of the National Academy of Sciences of the United States of America. 2018;115:2126-31.

39. Gallardo C, Fernandez-Pinero J, Arias M. African swine fever (ASF) diagnosis, an essential tool in the epidemiological investigation. Virus Res. 2019;271:197676.

40. Rodrigues ME, Costa AR, Henriques M, Azeredo J, Oliveira R. Technological progresses in monoclonal antibody production systems. Biotechnol Prog. 2010;26:332-51.

41. Pírez-Schirmer M, Rossotti M, Badagian N, Leizagoyen C, Brena B, González-Sapienza G. Comparison of Three Antihapten VHH Selection Strategies for the Development of Highly Sensitive Immunoassays for Microcystins. Analytical chemistry. 2017;89:6800-6.

42. Oviedo J, Rodríguez F, Gómez-Puertas P, Brun A, Gómez N, Alonso C, Escribano J. High level expression of the major antigenic African swine fever virus proteins p54 and p30 in baculovirus and their potential use as diagnostic reagents. Journal of virological methods. 1997;64:27-35. 
43. H HG, P FN. Indirect sandwich ELISA for antigen detection of African swine fever virus: comparison of polyclonal and monoclonal antibodies. Journal of virological methods. 2006;131.

44. L Z GNJ, G ZL. BT, F KG, L RD. Neutralizing antibodies to African swine fever virus proteins p30, p54, and p72 are not sufficient for antibody-mediated protection. Virology. 2004;319.

45. Hernáez B, Díaz-Gil G, García-Gallo M, Quetglas JI, Rodríguez-Crespo I, Dixon L, Escribano JM, Alonso C. The African swine fever virus dynein-binding protein p54 induces infected cell apoptosis. John Wiley \& Sons, Ltd. 2004;569.

46. Salas ML, Andrés G. African swine fever virus morphogenesis. Virus Research. 2013;173.

47. Petrovan V, Murgia MV, Wu P, Lowe AD, Jia W, Rowland RRR. Epitope mapping of African swine fever virus (ASFV) structural protein, p54. Virus Res. 2020;279:197871.

48. Gimenez-Lirola LG, Mur L, Rivera B, Mogler M, Sun Y, Lizano S, Goodell C, Harris DL, Rowland RR, Gallardo C, Sanchez-Vizcaino JM, Zimmerman J. Detection of African Swine Fever Virus Antibodies in Serum and Oral Fluid Specimens Using a Recombinant Protein 30 (p30) Dual Matrix Indirect ELISA. PLoS One. 2016;11:e0161230.

49. Sastre P, Perez T, Costa S, Yang X, Raber A, Blome S, Goller KV, Gallardo C, Tapia I, Garcia J, Sanz A, Rueda P. Development of a duplex lateral flow assay for simultaneous detection of antibodies against African and Classical swine fever viruses. J Vet Diagn Invest. 2016;28:543-9.

50. Gallardo C, Reis AL, Kalema-Zikusoka G, Malta J, Soler A, Blanco E, Parkhouse RME, Leitao A. Recombinant Antigen Targets for Serodiagnosis of African Swine Fever. Clinical Vaccine Immunology. 2009;16:1012-20.

51. Oura CAL, Edwards L, Batten CA. Virological diagnosis of African swine fever-Comparative study of available tests. Virus Research. 2013;173.

52. Liu H, Wang Y, Duan H, Zhang A, Liang C, Gao J, Zhang C, Huang B, Li Q, Li N, Xiao S, Zhou EM. An intracellularly expressed Nsp9-specific nanobody in MARC-145 cells inhibits porcine reproductive and respiratory syndrome virus replication. Vet Microbiol. 2015;181:252-60.

\section{Tables}

Tab. 1 Enrichment of Nbs against ASFV p54 protein from the phages via three rounds of panning

\begin{tabular}{|llllll|}
\hline $\begin{array}{l}\text { Round of } \\
\text { panning }\end{array}$ & $\begin{array}{l}\text { Input phage } \\
\text { (pfu/well) }\end{array}$ & $\begin{array}{l}\text { P } \\
\text { output [pfu/well }\end{array}$ & $\begin{array}{l}\text { N output } \\
\text { (pfu/well) }\end{array}$ & $\begin{array}{l}\text { Recovery } \\
\text { पP/Input口 }\end{array}$ & $\mathrm{P} / \mathrm{N}$ \\
\hline 1st round & $5 \times 10^{10}$ & $4.5 \times 10^{4}$ & $2.8 \times 10^{4}$ & $9 \times 10^{-7}$ & 1.6 \\
\hline $2^{\text {nd }}$ round & $5 \times 10^{10}$ & $3.4 \times 10^{6}$ & $1.2 \times 10^{5}$ & $6.8 \times 10^{-5}$ & 28.3 \\
\hline $3^{\text {rd }}$ round & $5 \times 10^{10}$ & $2.7 \times 10^{8}$ & $1.1 \times 10^{5}$ & $5.4 \times 10^{-3}$ & $2.5 \times 10^{-3}$ \\
\hline
\end{tabular}


Tab.2 Comparison of the blocking ELISA with a commercial ELISA kit

\begin{tabular}{|c|c|c|c|c|c|c|}
\hline \multicolumn{2}{|c|}{ Methods and serum samples } & \multicolumn{3}{|c|}{ Commercialization ELISA } & \multirow{3}{*}{$\begin{array}{l}\text { Coincidence } \\
\text { rate } \\
\text { (CR) }\end{array}$} & \multirow[t]{3}{*}{ kappa } \\
\hline & & $\begin{array}{l}\text { Positive } \\
\text { serum }\end{array}$ & $\begin{array}{l}\text { Negative serum } \\
\text { numbers }\end{array}$ & Total & & \\
\hline & & numbers & & & & \\
\hline \multirow{5}{*}{$\begin{array}{l}\text { Blocking } \\
\text { ELISA }\end{array}$} & Positive serum & 14 & 3 & 17 & $82.35 \%$ & \\
\hline & numbers & & & & & \\
\hline & & & & & & 0.8962 \\
\hline & $\begin{array}{l}\text { Negative serum } \\
\text { numbers }\end{array}$ & 0 & 193 & 193 & $100 \%$ & \\
\hline & Total & 14 & 196 & 210 & $98.57 \%$ & \\
\hline
\end{tabular}

\section{Figures}


A

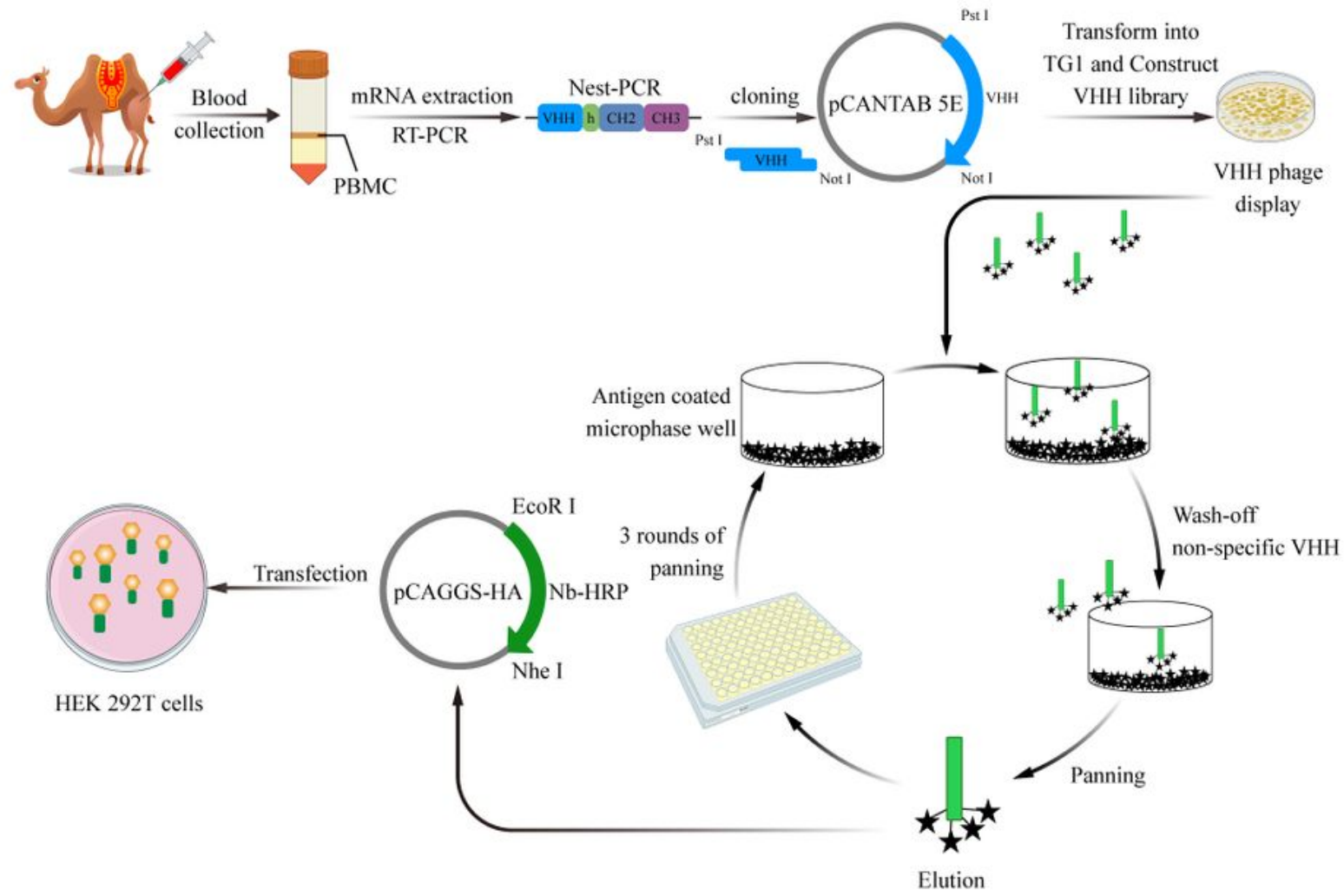

$\mathrm{B}$

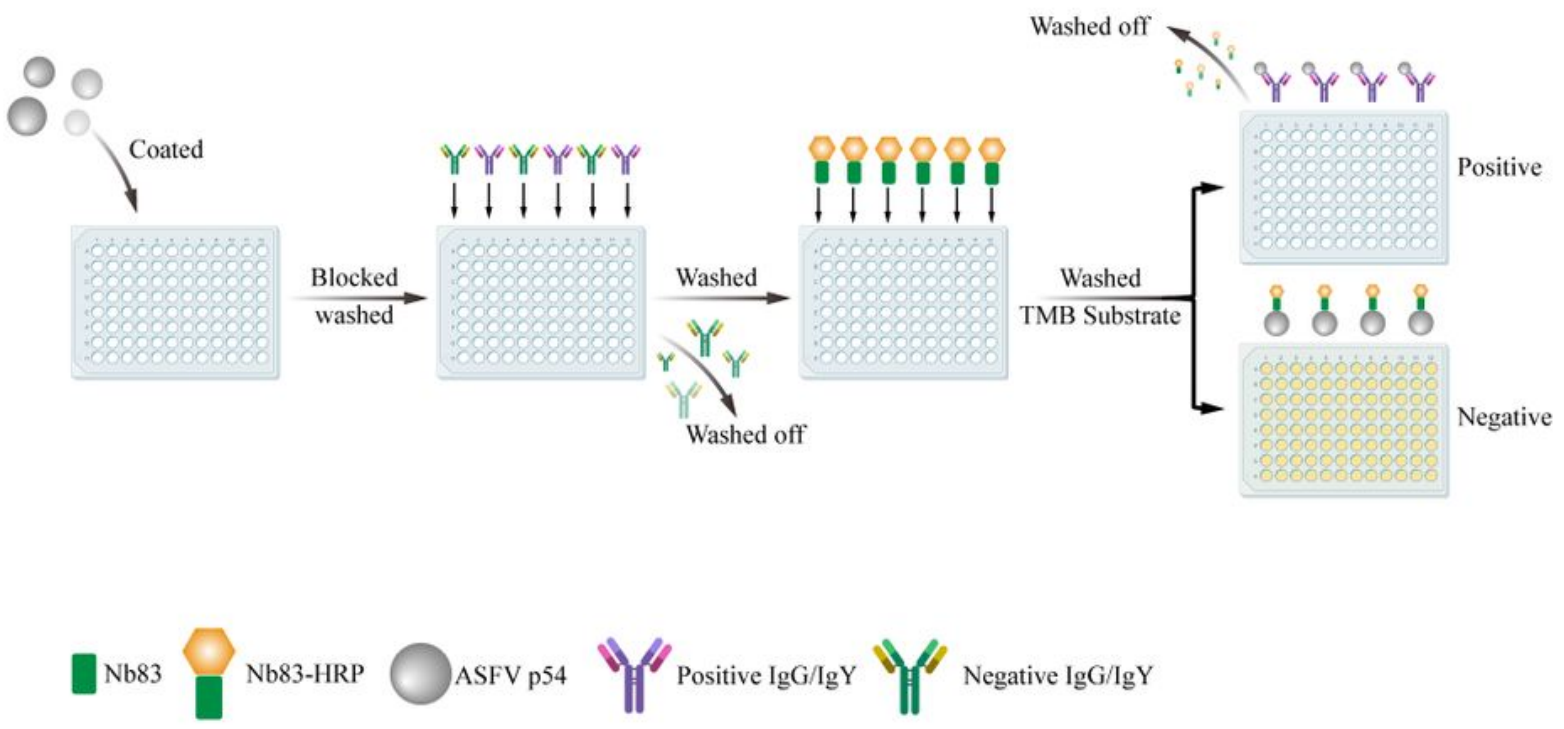

\section{Figure 1}

Schematic representation of developing the blocking ELISA to detect ASFV serum antibody. 


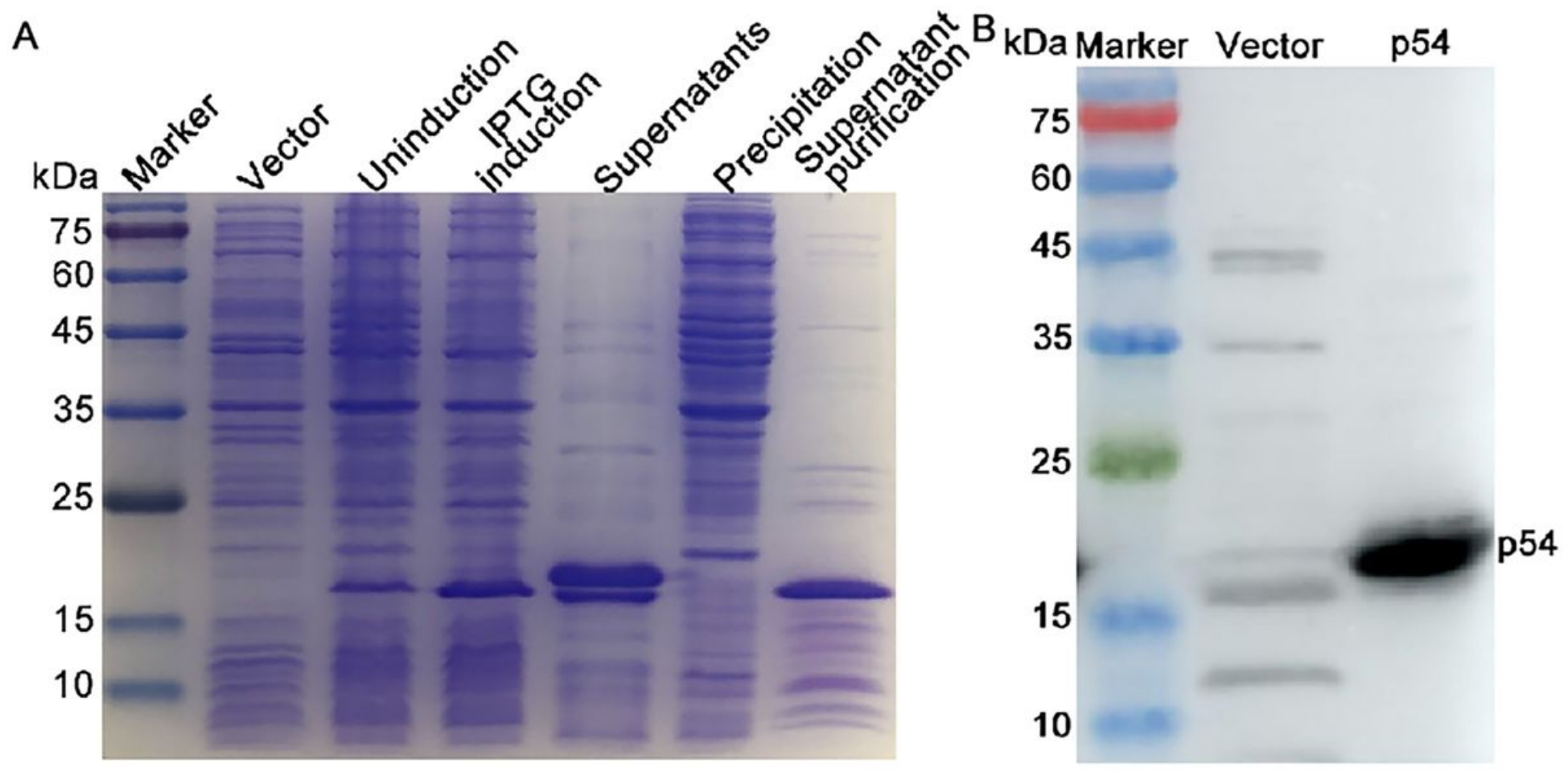

Figure 2

Expression and purification of p54 protein. (A) Transetta DE3 competent cells transformed with pET-30p54-His plasmids were induced or not with $1.0 \mathrm{mM}$ IPTG for $12 \mathrm{~h}$. After ultrasonication and centrifugation, supernatants or precipitation were subjected to SDS-PAGE analysis. (B) Purified p54 protein was verified using Western blotting with inactivated ASFV-positive pig serum. Abbreviations: ASFV: African swine fever virus; IPTG: isopropyl $\beta$-D-thiogalactoside. 


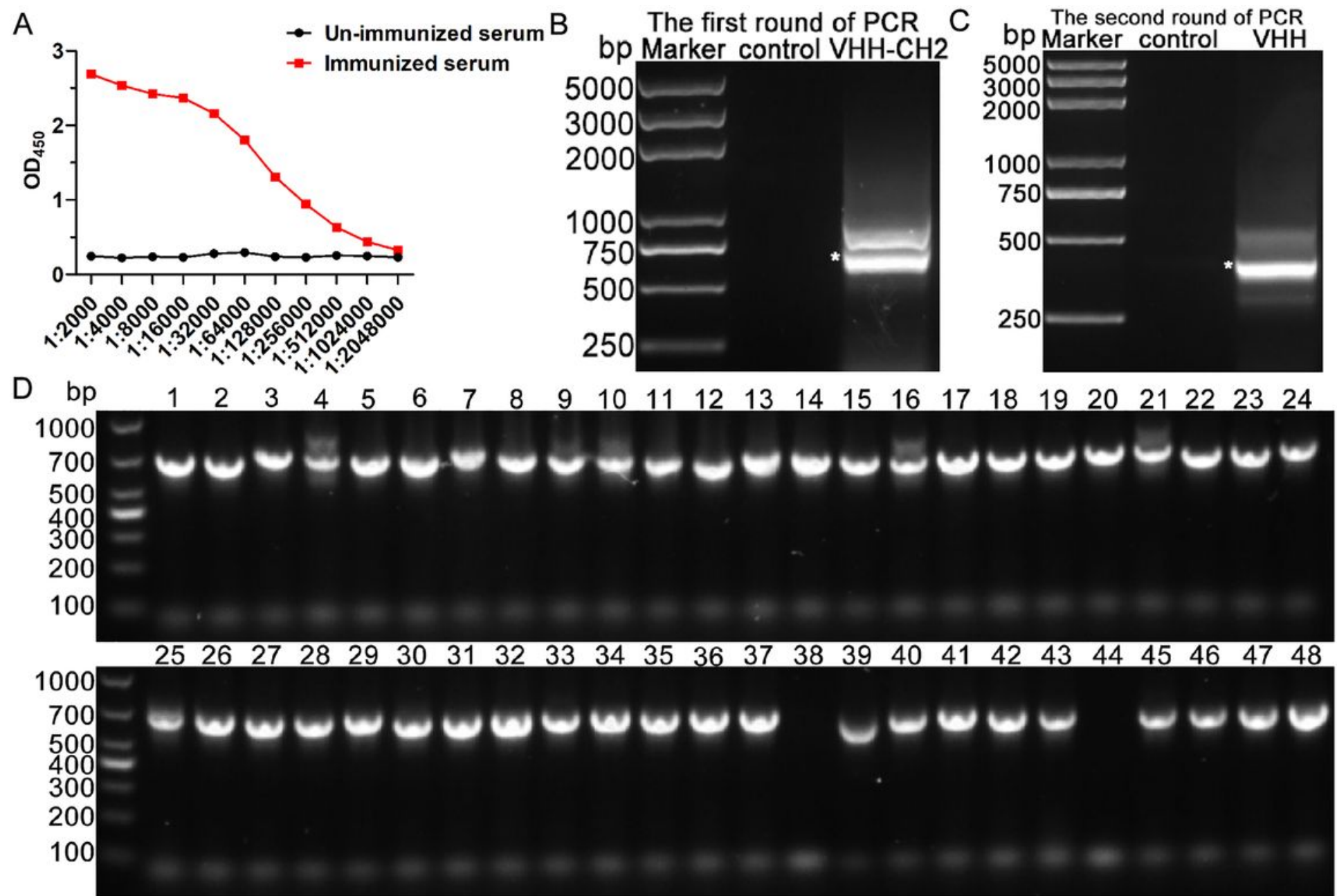

$\mathrm{E}$
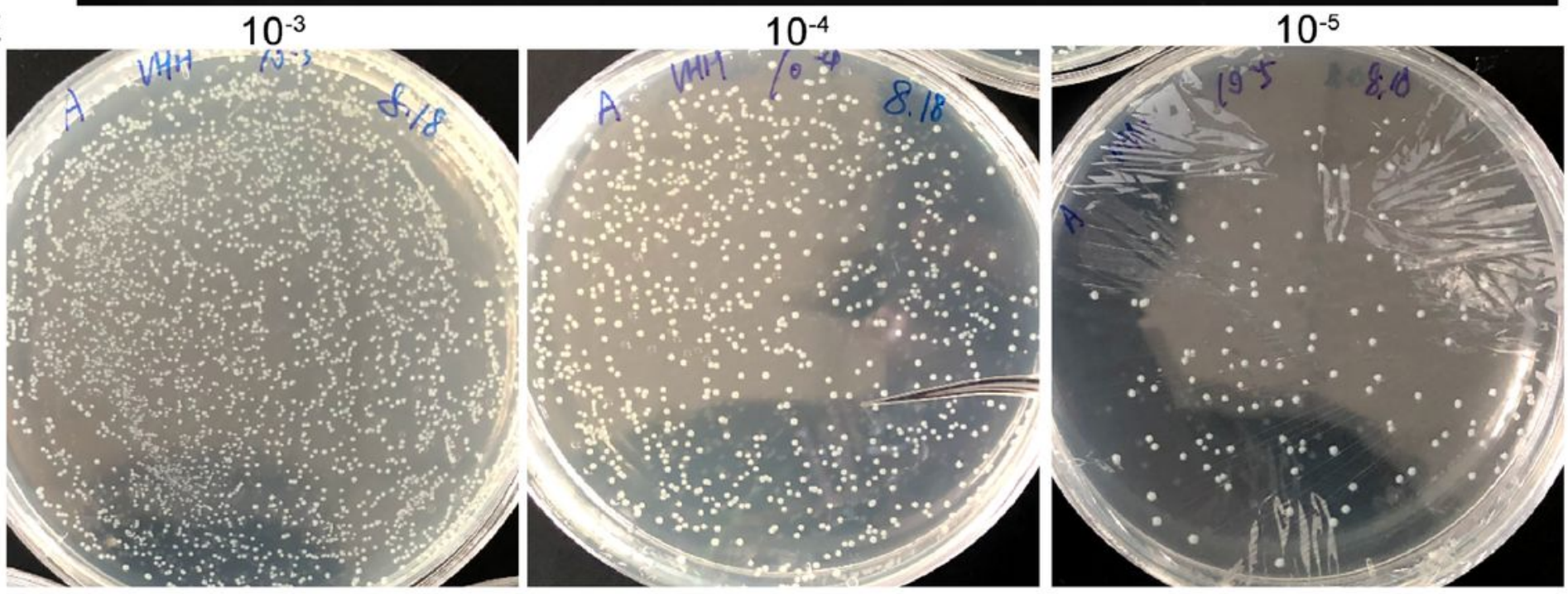

Figure 3

Bactrian camel immunization and construction of phage library of $\mathrm{VHH}$. (A) A male bactrian camel was immunized with purified p54 protein ( $5 \mathrm{mg}$ per immunization) together with Freund's adjuvant. One week after the forth immunization, serum was separated and the titer was determined using indirect ELISA. (B and C) Total RNA extracted from camel PBLs was reversed transcripted into cDNA and used as the templates of the first round of PCR, and VHH gene was obtained by the second round of PCR. After 
pCANTAB 5E-Nbs were electroporated into the TG1 competent cells, $100 \mu$ l of the transformation products were used to coat on the LB plate and 48 clones were picked randomly $16 \mathrm{~h}$ later and identified with PCR (D); the resting bacteria was serially diluted and coated on the LB plate for analysis of library size (E). Abbreviations: PCR: polymerase chain reaction; ELISA: enzyme-linked immunosorbent assay; PBLs: peripheral blood lymphocytes.

A

Clones $1-48$
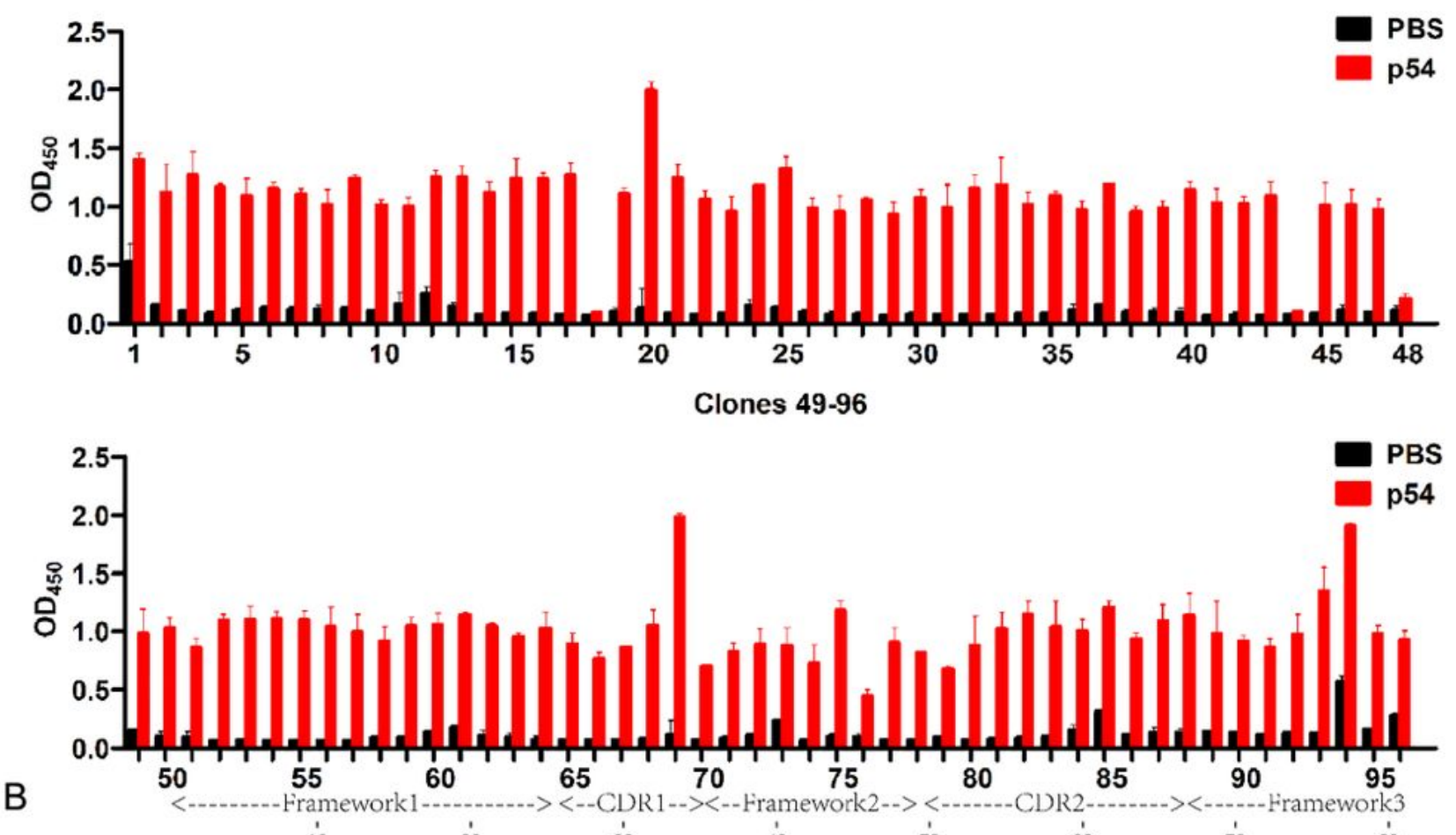

10

20

30

40

$50 \quad 60$

70

ASI:V-P54-Nb2 QVQLQESGGGSAQAGGSLRLSCAASGFTYSNYLMGWFRQAPGKGLEWVSSIYTGGGSTYYADSVKGRFTI SKDNAKNTLY $\frac{1}{1}$ ASFV-P54-Nh83 QVQLQESGGGSAQAGGSLRLSCAASGYTYSLPFMAWFRQAPGKEREGVAVI APGAGMAYYASSVKGRFTI SQANAKNTVY 238 ASFV-P54-Nb86 QVQLQESGGGSVQAGGSLKLSCKVSGDI F SSCGMGWYRQAPGKDQEWWASI WRDGSDAEYADSVKGRF TI SRDNAKNTVY 238 ASFV-P54-Nb89 QVQLQESGGGSVQAGGSLRLACTADGYTSSVVYMGWFRQAPGKEREGVAII PTHGGSTYYADSVKDRFTI SQADARNTLY 238 ASFV-P54-Nb96 QVQLQESGGGSVQAGGSLRLSCTASGF TFDDSDMGWYRQAPANECALVSTI SSD. GSTYYADSVKGRF TI SRDNRKNTVY 235

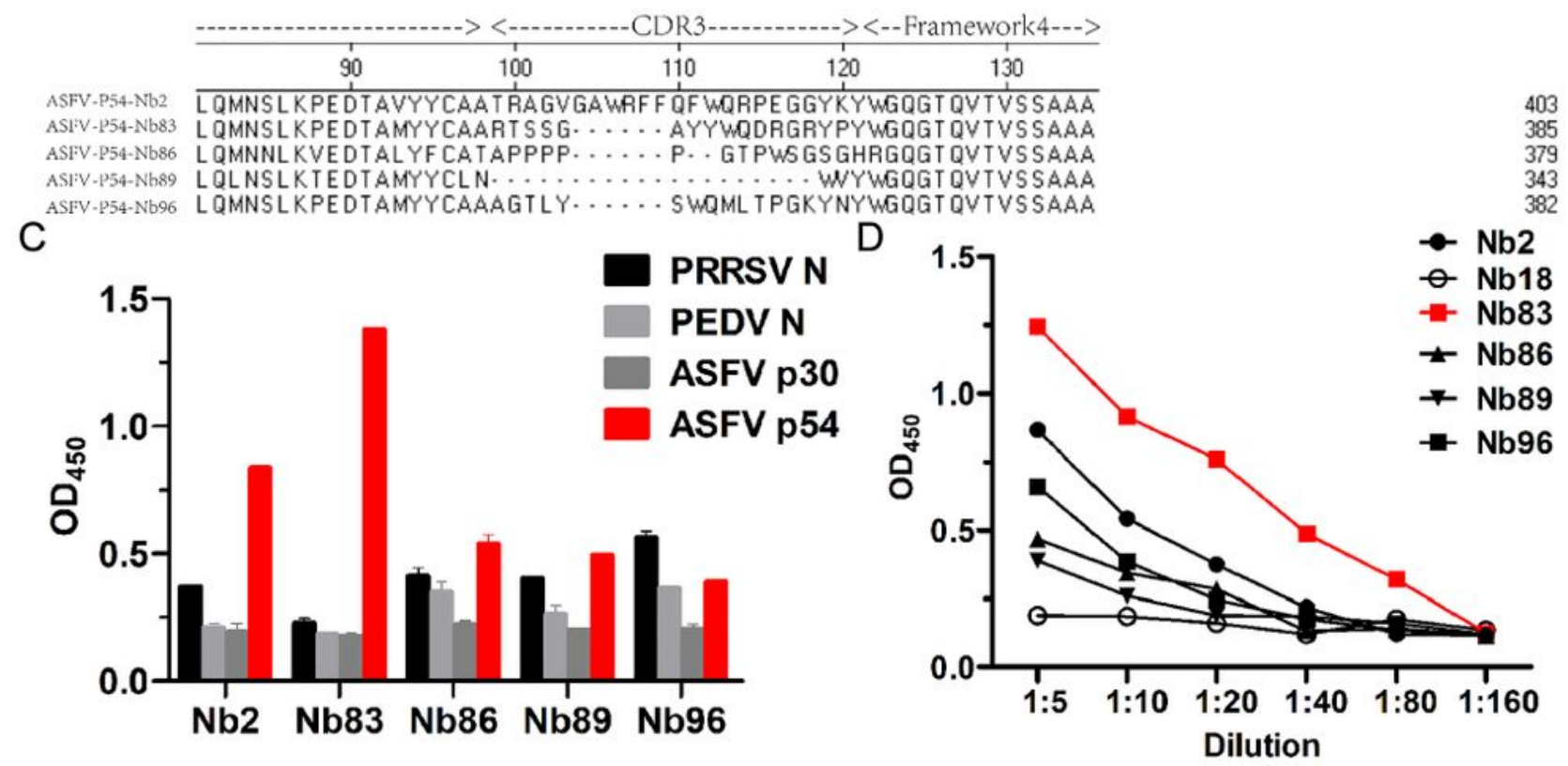

Figure 4 
Specificity and reactivity of isolated Nbs against the ASFV p54 protein. (A) Indirect ELISA analysis of periplasmic extracts reacted with the ASFV p54 protein from 96 clones. (B) Amino acid sequence alignment of isolated $\mathrm{Nbs}$. Numbering and CDRs were determined as previously described (52). (C) Specificity detection of five Nbs against p54 protein using an indirect ELISA. (D) The affinity of the five $\mathrm{Nbs}$ to the p54 protein was detected using an indirect ELISA. ASFV, African swine fever virus; Nbs, nanobodies; CDRs, complementary-determining regions; ELISA, enzyme-linked immunosorbent assay; HRP, horseradish peroxidase; Ig, immunoglobin.

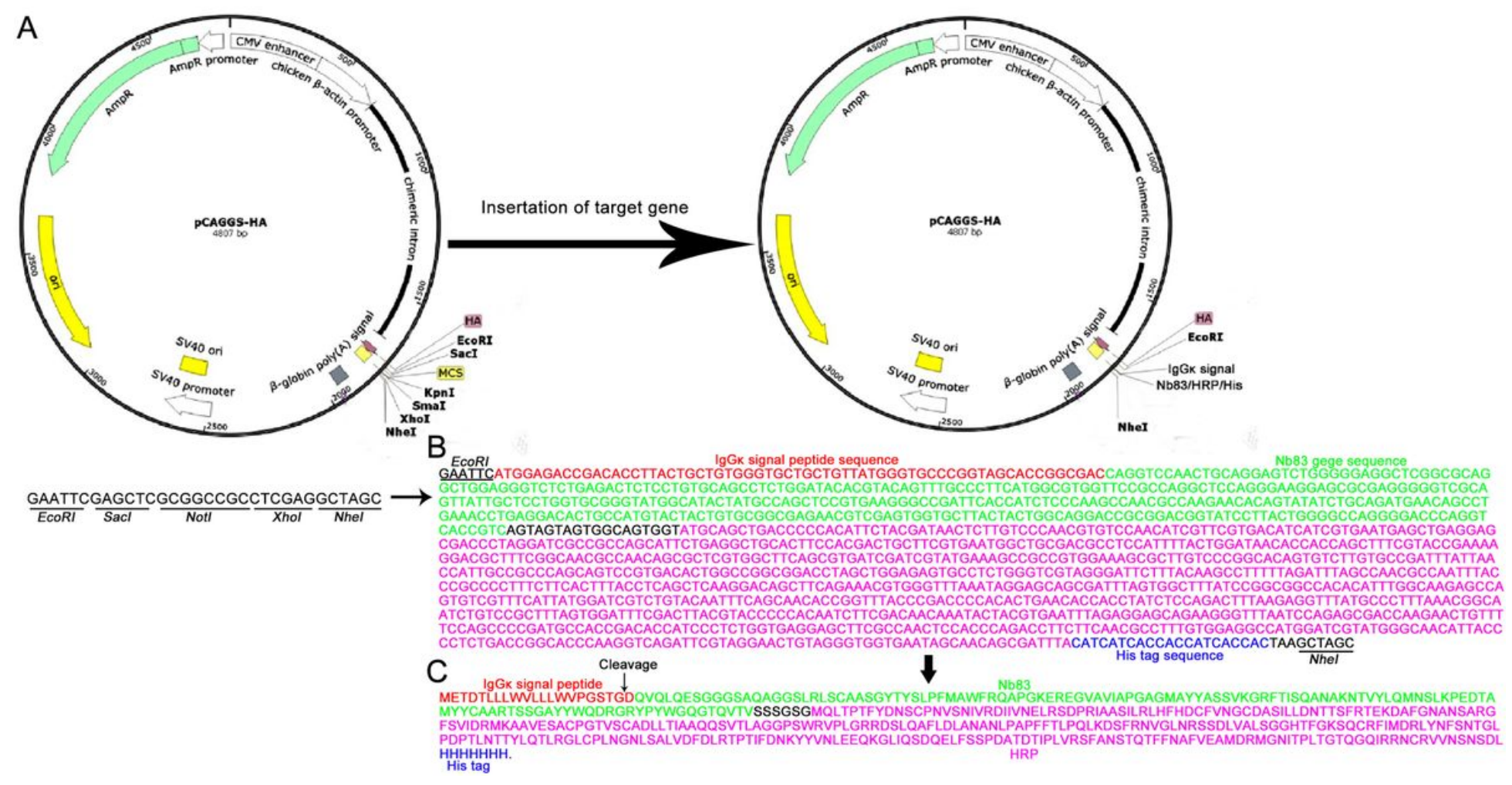

\section{Figure 5}

Construction of Nb83-HRP eukaryotic expression system. (A) Shematic of eukaryotic expression vector expressing Nb83-HRP. (B) Nucleotide base sequence of IgGK and Nb83-HRP. (C) Amino acid sequence of IgGK and Nb83-HRP encoded by eukaryotic expression vector pCAGGS-HA. Abbreviations: IgGK: human immunoglobin G kappa chain; HRP: horseradish peroxidase. 
A

B
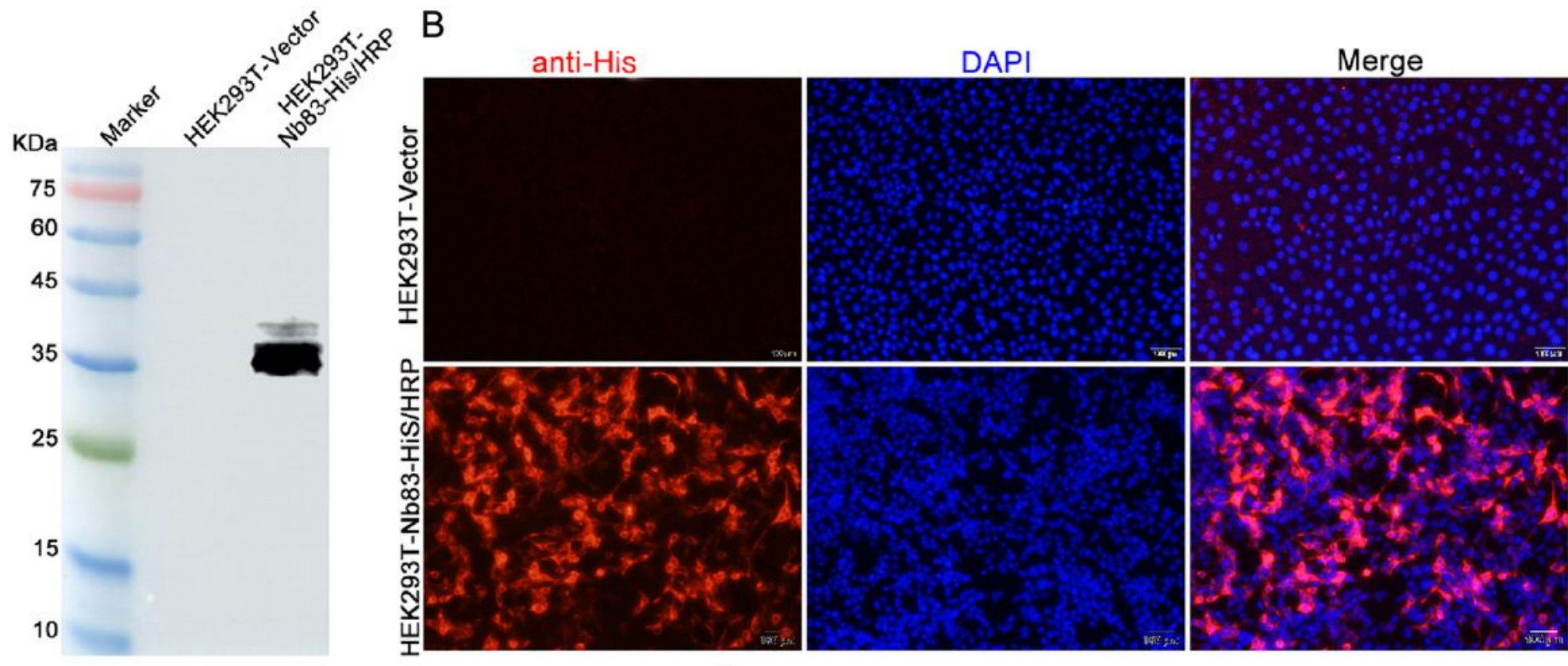

C

PRRSV N D

PEDV N
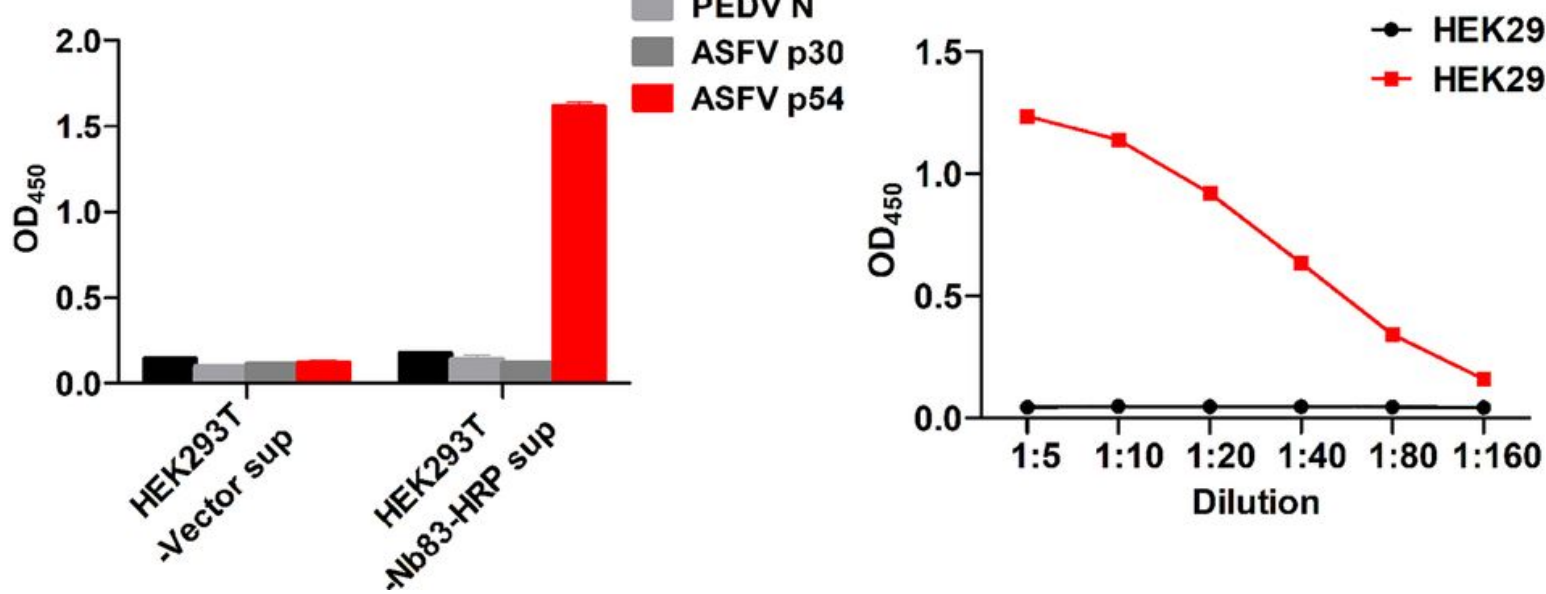

Figure 6

Expression and identification of Nb83-HRP fusion protein in 293T cells. (A) pCAGGS-Nb83-HRP recombinant plasmids were transfected into $293 \mathrm{~T}$ cells for $36 \mathrm{~h}$. Cells were harvested for Nb83-HRP analysis using western blotting with mouse anti-HA mAb as the primary antibody and HRP-conjugated goat anti-mouse IgG as the secondary antibody. At $36 \mathrm{~h}$ post-pCAGGS-Nb83-HRP transfection, 293T cell culture supernatants were harvested for (B) Nb83-HRP specificity and (C) affinity assay to ASFV p54 protein using a direct ELISA. Nb, nanobody; IgG, immunoglobin G; ASFV, African swine fever virus; ELISA, enzyme-linked immunosorbent assay; HRP, horseradish peroxidase; mAb, monoclonal antibody; HA, hemagglutinin. 
A

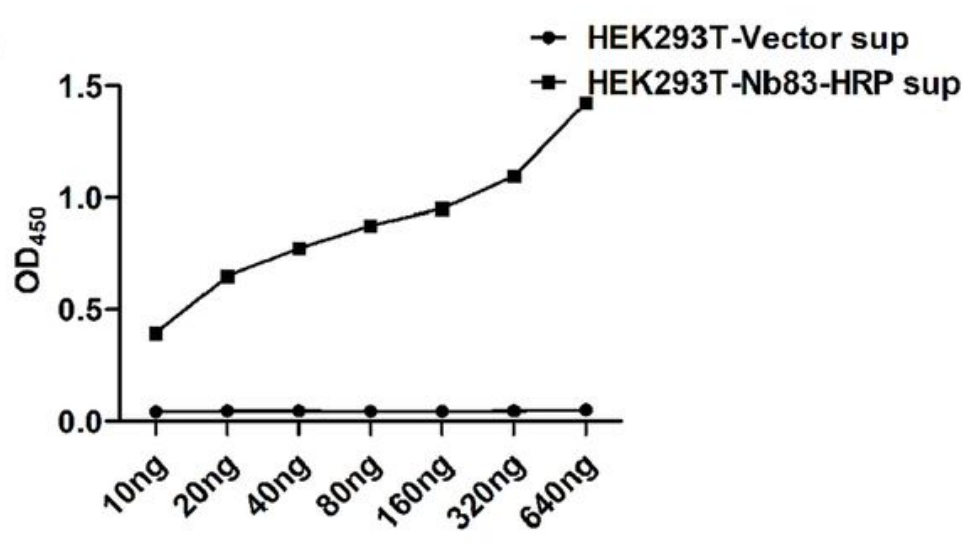

C

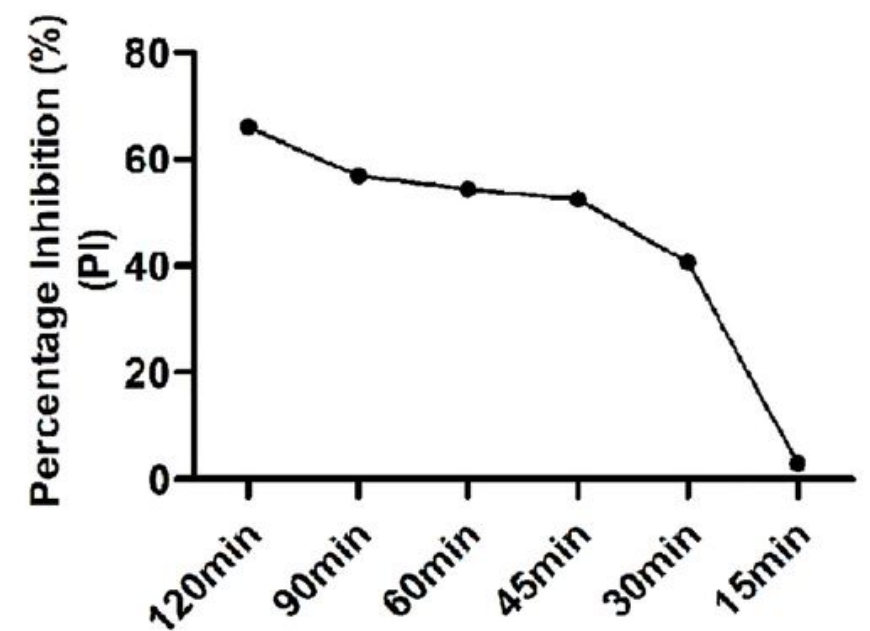

Serum incubation time

E

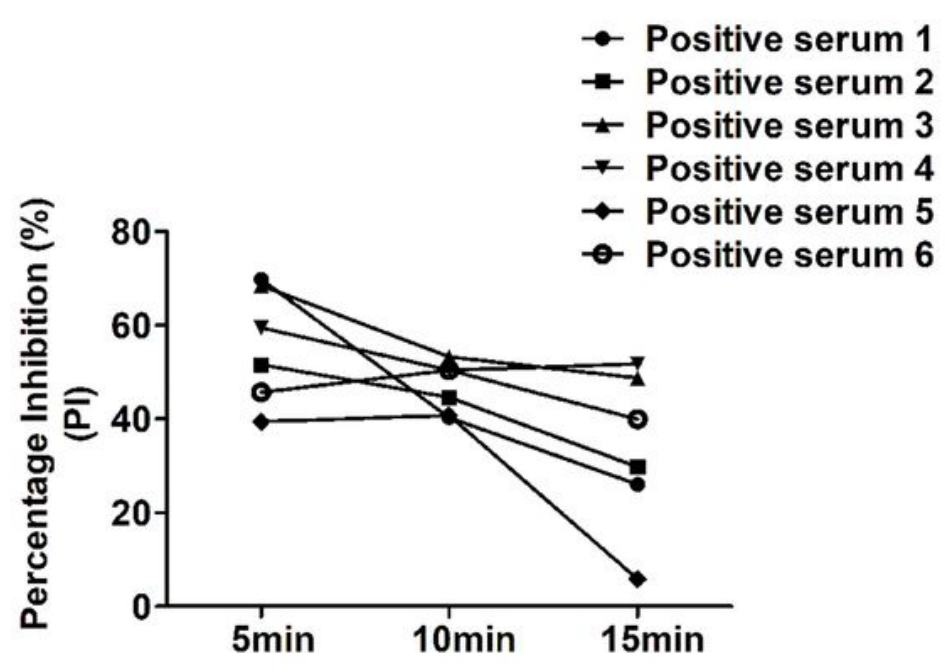

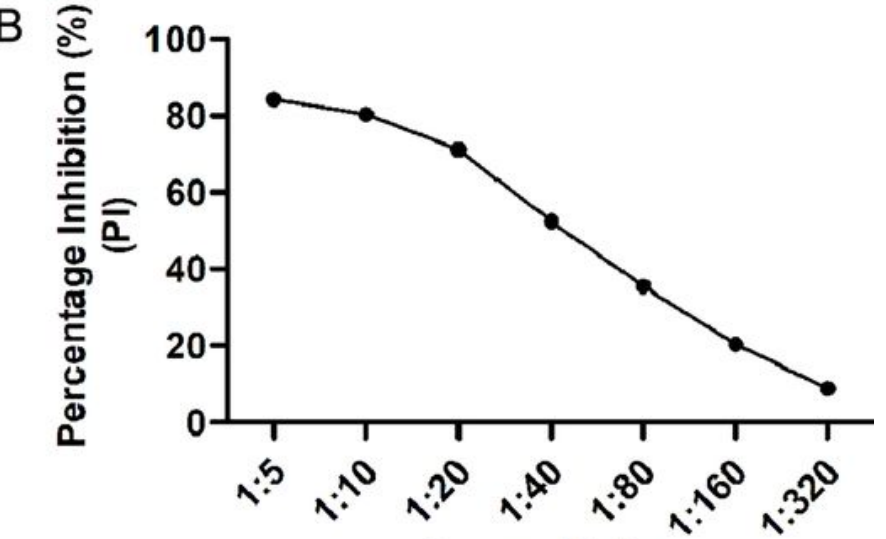

D

Serum dilution

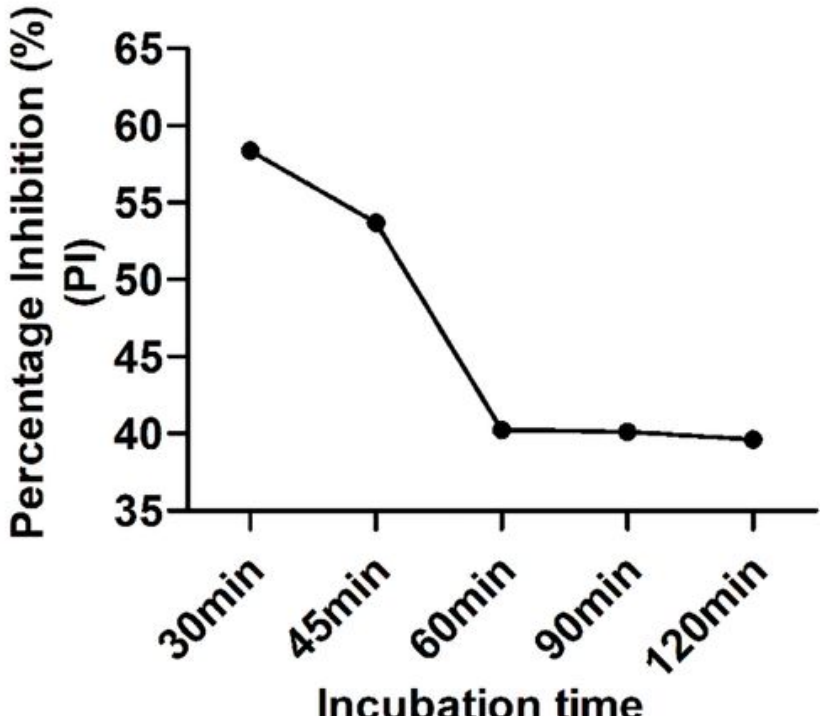

Figure 7

Optimization of blocking ELISA reaction conditions. (A) Optimal concentration of p54 protein and supernatant Nb83-HRP optimum dilution ratio was determined by direct ELISA when the OD450 value reaches 1.0. (B) The optimal serum dilution was determined when the PI value was highest. The optimal serum (C) and supernatant Nb83-HRP (D) incubation time were determined by utilizing a checkerboard titration assay when the $\mathrm{P} / \mathrm{N}$ ratio was highest. (E) The optimal colorimetric reaction time was determined 
based on detection of 3 inactivated ASFV antibody-positive and 3 ASFV antibody-negative serum samples. Abbreviations: Nb: nanobody; ASFV: African swine fever virus; ELISA: enzyme-linked immunosorbent assay; HRP: horseradish peroxidase; PI: percentage inhibition.

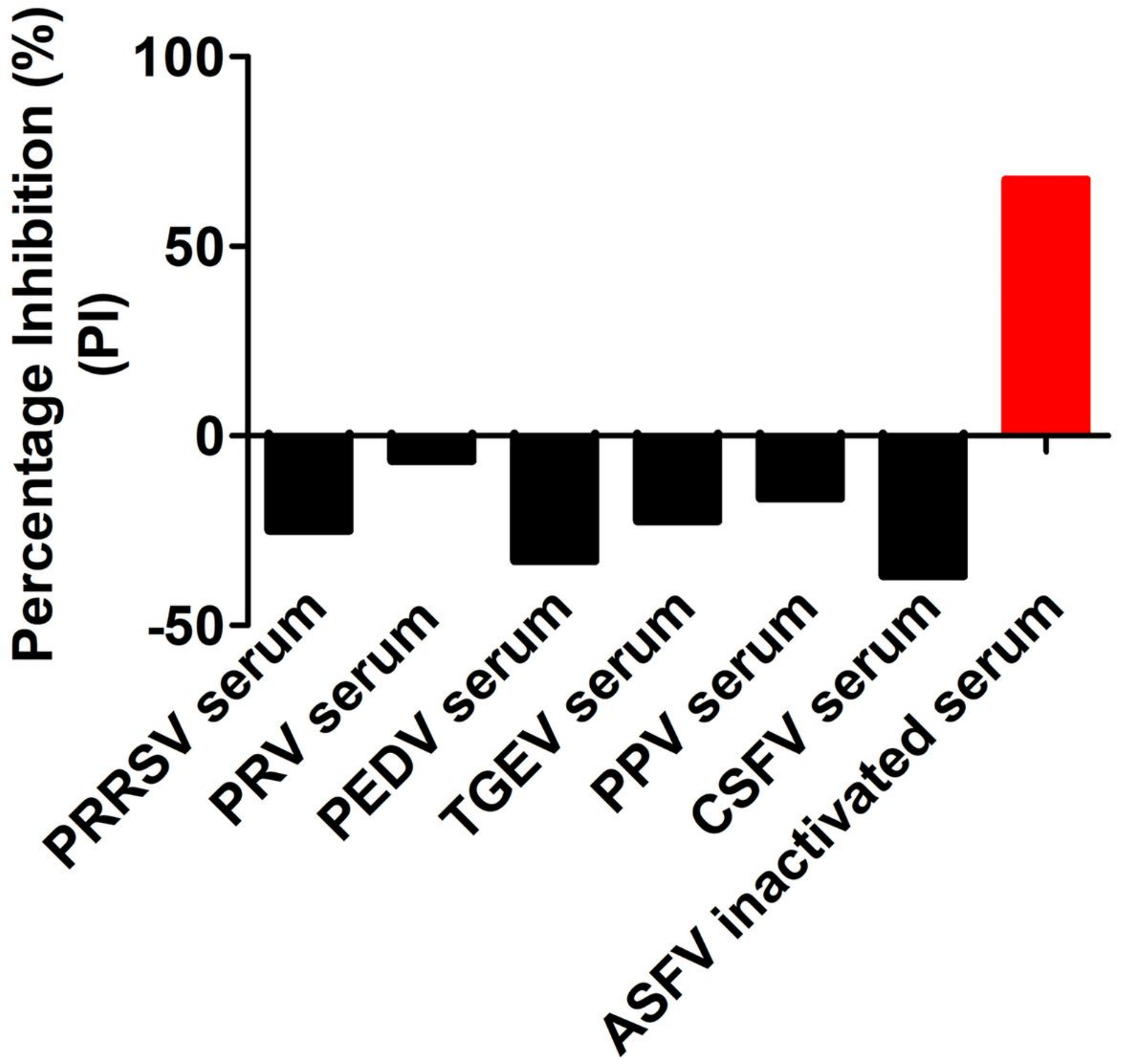

Figure 8

Specificity verification of the developed blocking ELISA. PRRSV-, PRV-, PEDV-, TGEV-, PPV-, CSFV- and inactivated ASFV antibody-positive serums were reacted with p54 protein (320 ng/well) and used to coat 96-well plates to determine the specificity of the developed blocking ELISA. PRRSV, porcine reproductive and respiratory syndrome virus; PRV, pseudorabies virus; PEDV, porcine epidemic diarrhea virus; TGEV, porcine transmissible gastroenteritis virus; PPV, porcine parvovirus; CSFV, classical swine fever virus; 


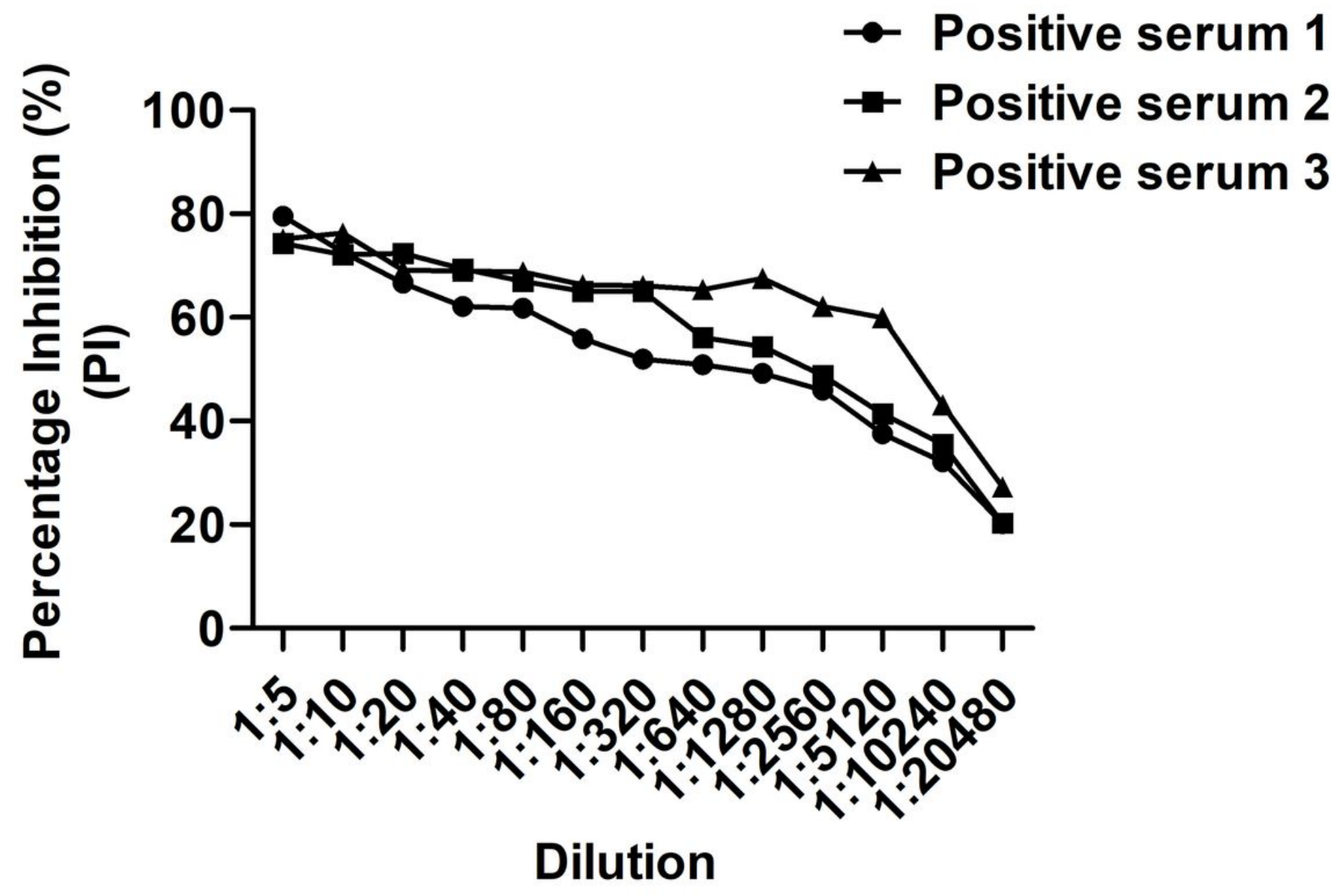

Figure 9

Sensitivity analysis of the developed blocking ELISA. A total of three different inactivated ASFV antibodypositive serums (dilutions, 1:5, 1:10, 1:20, 1:40, 1:80, 1:160, 1:320, 1:640, 1:1,280, 1:2,560, 1:5,120, 1:10,240 and 1:20,480) were incubated in 96-well plates coated with ASFV p54 protein ( $320 \mathrm{ng} / \mathrm{well})$ to evaluate the sensitivity of the developed blocking ELISA. Percentage inhibition was determined according to the OD450 value. Three replicate wells were used for each sample. The data are presented as the mean \pm SD. ELISA, enzyme-linked immunosorbent assay; ASFV, African swine fever virus; OD, optical density. 
- Negative serum 3

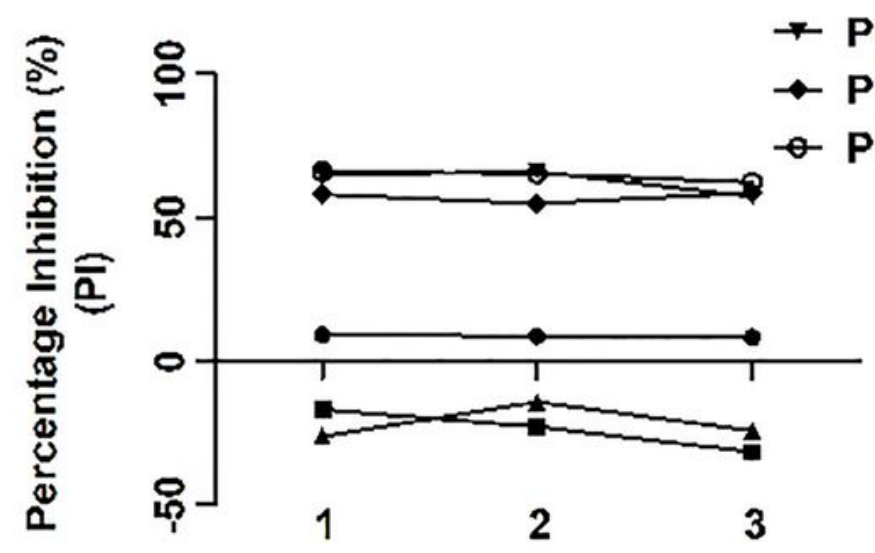

B

Experiment Number

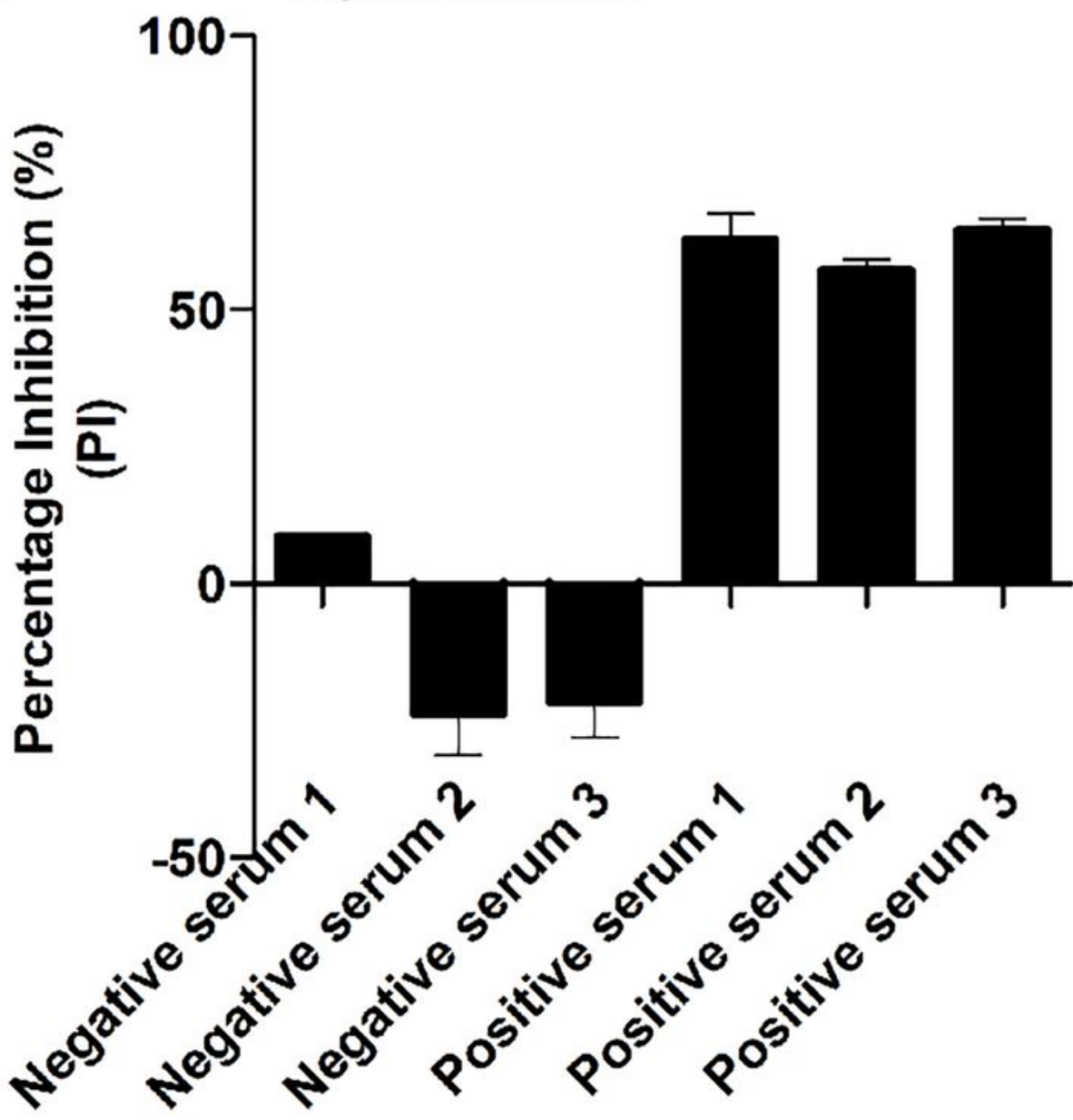

Figure 10

Repeatability analysis of the developed blocking ELISA. (A) For intra-assay repeatability test, three ASFVnegative serum samples and three inactivated ASFV-positive serum samples were detected using the blocking ELISA, and the same batch of p54 protein-coated ELISA plates was tested three times. Each serum sample was also tested three times. (B) For the inter-assay repeatability test, different batches of plates were tested separately three times. Each serum sample was also tested three times. The PI was 
calculated based on the OD450 value. The results are presented as the mean \pm SD of the PI value of each group of samples. ASFV, African swine fever virus; ELISA, enzyme-linked immunosorbent assay; PI, percentage inhibition; OD, optical density.

\section{NC sample 1 NC sample 2 NC sample 3 NC ${ }^{\text {positive serum }}$}

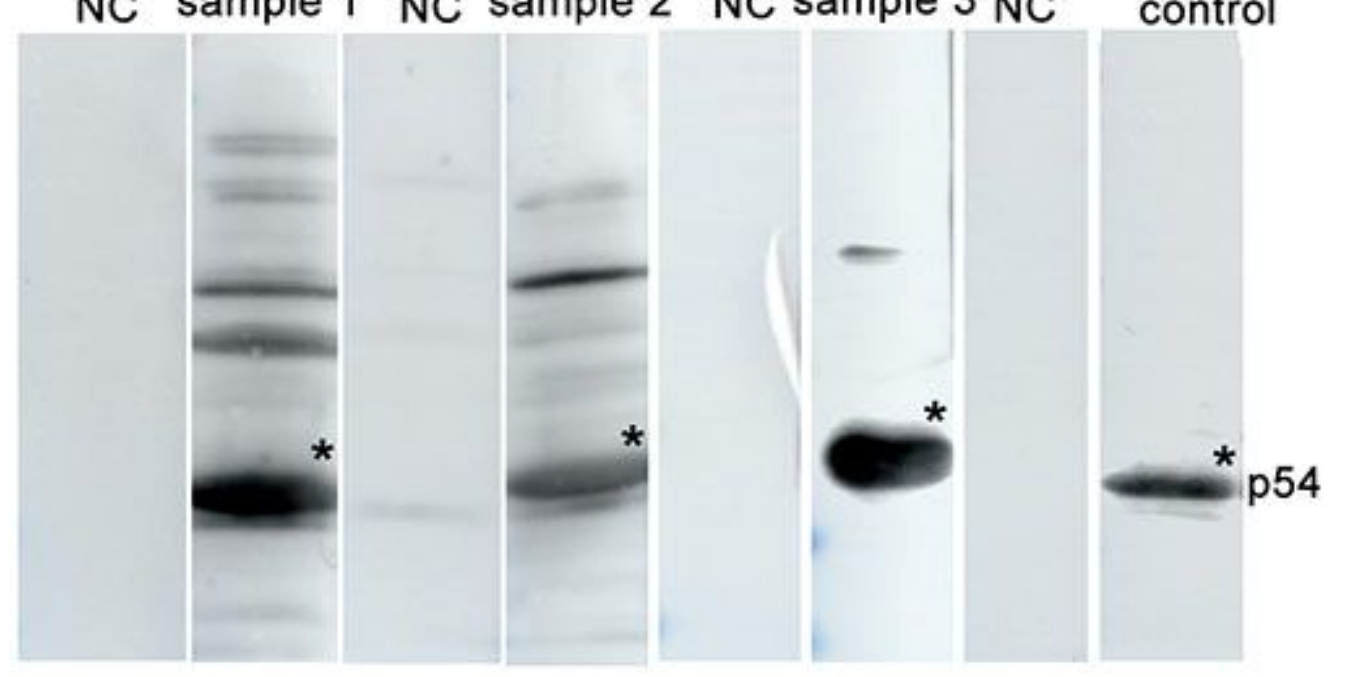

\section{Figure 11}

Evaluation of the discrepancy of test results between the blocking ELISA and commercial ELISA kit. Western blotting of the three swine serum samples with a discrepant result between the developed blocking ELISA and commercial ELISA kit. A negative serum and a inactivated standard ASFV antibodypositive serum were used simultaneously as the control. ELISA, enzyme-linked immunosorbent assay. 